\title{
A Novel Size-Based Sorting Mechanism of Pinocytic Luminal Cargoes in Microglia
}

\author{
Cong Chen, ${ }^{1 \star}$ Hui-Quan Li, ${ }^{1 \star}$ Yi-jun Liu, ${ }^{1}$ Zhi-fei Guo, ${ }^{1}$ Hang-jun Wu, ${ }^{1}$ Xia Li, ${ }^{1}$ Hui-Fang Lou, ${ }^{1}$ Liya Zhu, ${ }^{1}$ Di Wang, ${ }^{2}$ \\ Xiao-Ming Li, ${ }^{1}$ Li Yu, ${ }^{3}$ Xuetao Cao, ${ }^{2,4}$ Linrong Lu, ${ }^{2}$ Zhihua Gao, ${ }^{1}$ and Shu-Min Duan ${ }^{1}$ \\ ${ }^{1}$ Department of Neurobiology, Key Laboratory of Medical Neurobiology of The Ministry of Health of China, Key Laboratory of Neurobiology of Zhejiang \\ Province, and ${ }^{2}$ Institute of Immunology, Zhejiang University School of Medicine, Hangzhou 310058, China, ${ }^{3}$ State Key Laboratory of Biomembrane and \\ Membrane Biotechnology, Tsinghua University-Peking University Joint Center for Life Sciences, School of Life Sciences, Tsinghua University, Beijing \\ 100084, China, and ${ }^{4}$ National Key Laboratory of Medical Immunology and Institute of Immunology, Second Military Medical University, Shanghai 200433, \\ China
}

Microglia are the resident immune cells in the CNS and play diverse roles in the maintenance of CNS homeostasis. Recent studies have shown that microglia continually survey the CNS microenvironment and scavenge cell debris and aberrant proteins by phagocytosis and pinocytosis, and that reactive microglia are capable to present antigens to $\mathrm{T}$ cells and initiate immune responses. However, how microglia process the endocytosed contents and evoke an immune response remain unclear. Here we report that a size-dependent selective transport of small soluble contents from the pinosomal lumen into lysosomes is critical for the antigen processing in microglia. Using fluorescent probes and water-soluble magnetic nanobeads of defined sizes, we showed in cultured rodent microglia, and in a cell-free reconstructed system that pinocytosed proteins become degraded immediately following pinocytosis and the resulting peptides are selectively delivered to major histocompatibility complex class II (MHC-II) containing lysosomes, whereas undegraded proteins are retained in the pinosomal lumen. This early size-based sorting of pinosomal contents relied on the formation of transient tunnel between pinosomes and lysosomes in a Rab7- and dynamin II-dependent manner, which allowed the small contents to pass through but restricted large ones. Inhibition of the size-based sorting markedly reduced proliferation and cytokine release of cocultured CD4 ${ }^{+} \mathrm{T}$ cells, indicating that the size-based sorting is required for efficient antigen presentation by microglial cells. Together, these findings reveal a novel early sorting mechanism for pinosomal luminal contents in microglial cells, which may explain how microglia efficiently process protein antigens and evoke an immune response.

Key words: antigen presentation; endocytic trafficking; luminal contents; lysosome; microglia; size-based sorting

\section{Introduction}

Microglia are innate immune cells in the CNS and are critically involved in responses to neural lesion and tumors, as well as various brain diseases, including autoimmune, infectious, and neurodegenerative diseases (Aloisi, 2001; Saijo and Glass, 2011).

Received Oct. 22, 2014; revised Dec. 19, 2014; accepted Dec. 24, 2014.

Author contributions: C.C., H.-Q.L., L.Y., L.L., Z.G., and S.-M.D. designed research; C.C. and H.-Q.L. performed research; Y.-j.L., Z.-f.G., H.-j.W., X.L., H.-F.L., L.Z., D.W., X.-M.L., L.Y., X.C., and L.L. contributed unpublished reagents/analytic tools; C.C. and H.-Q.L. analyzed data; C.C., H.-Q.L., Z.G., and S.-M.D. wrote the paper.

This work was supported by grants from the Major State Basic Research Program of China (2011CB504400), the National Natural Science Foundation of China (31190060, 31490590, 91232000, 81221003, and 31471308), the National Key Technology R\&D Program of the ministry of Science and Technology of China (2012BA101B08), the Program for Introducing Talents in Discipline to Universities, and the Zhejiang Provincial Natural Science Foundation of China (Y2110057), and the Fundamental Research Funds for the Central Universities (2014FZA7007). We thank Dr Mu-ming Poo and Dr lain C. Bruce for critical comments on the paper and Dr Tuan-lao Wang for generously providing the wild-type, dominant-negative, and constitutively active forms of Rab7 constructs.

The authors declare no competing financial interests.

${ }^{*}$ C.C. and H.-Q.L. contributed equally to this work.

Correspondence should be addressed to either Shu-Min Duan or Zhihua Gao, Department of Neurobiology, Key Laboratory of Medical Neurobiology of The Ministry of Health of China, Key Laboratory of Neurobiology of Zhejiang Province, Zhejiang School of Medicine, Hangzhou 310058, China, E-mail: duanshumin@zju.edu.cn or zhihuagao@zju.edu.cn.

DOI:10.1523/JNEUROSCI.4389-14.2015

Copyright $\odot 2015$ the authors $\quad 0270-6474 / 15 / 352674-15 \$ 15.00 / 0$
Recent studies have shown that microglia continually monitor their microenvironment through pinocytosis (engulfment), even in their "resting" form (Nimmerjahn et al., 2005). Moreover, in pathological conditions, such as experimental autoimmune encephalomyelitis (EAE) model of multiple sclerosis, microglia are thought to play essential roles in recruiting immune cells to CNS and initiating an immune responses (Heppner et al., 2005). However, other than digestion, how microglia process the endocytosed contents remains unknown. It is well established that internalized membrane-associated proteins, mostly receptors, are selectively delivered to different intracellular compartments during the endosomal maturation (Harding et al., 1983; Davis et al., 1987; Whistler et al., 2002; Maxfield and McGraw, 2004; Bonifacino and Rojas, 2006). Yet, little is known about the trafficking mechanism of soluble contents in the endocytic lumen.

Pinocytosis, a form of endocytosis by which bulk extracellular fluids and soluble materials are nonselectively engulfed, has recently been linked to a number of physiological and pathological processes (Kerr and Teasdale, 2009; Commisso et al., 2013; Li et al., 2013). Via pinocytosis, exogenous antigens are taken up by antigen-presenting cells, such as macrophages and dendritic cells (Sodhi and Gupta, 1988; Lanzavecchia, 1996; Sarkar et al., 2005). 
We have previously demonstrated that ATP, and its nonhydrolyzable analog ATP $\gamma \mathrm{S}$, immediately induces pinocytosis in cultured rodent microglia (Li et al., 2013; Wu et al., 2014). The formed pinosomes are large, up to $\sim 5 \mu \mathrm{m}$ in diameter, thereby serving as a particularly good model to investigate the trafficking of engulfed soluble contents, including exogenous antigens, through imaging and biochemical analysis with high spatiotemporal precision. This approach led to the discovery of a novel size-dependent delivery of small luminal contents from pinosomes to lysosomes, a process involving both fusion and fission events. Further evidence demonstrated that the sizedependent delivery mechanism increased the efficiency of antigen presentation in microglia, explaining why microglial cells have antigen presenting ability even though with a low expression level of major histocompatibility complex (MHC).

\section{Materials and Methods}

\section{Cell culture}

All animal experiments were approved by the Zhejiang University Animal Care and Use Committee, and were in accordance with the guideline of the Care and Use of Laboratory Animal at Zhejiang University (Hangzhou, China).

Primary rat microglia were cultured as previously described (Dou et al., 2012). In brief, a mixed glial culture was prepared from the cerebral cortex of neonatal Sprague-Dawley rats (either sex) and maintained for $6-8 \mathrm{~d}$ in minimum essential medium (MEM) supplemented with $10 \%$ fetal bovine serum (FBS). Microglia were identified as floating cells over the mixed glial culture and collected by gentle shaking. For further experiments, microglia were concentrated for electrotransfection or directly transferred to glass coverslips and maintained in MEM containing $2 \%$ FBS for $12-16 \mathrm{~h}$.

\section{Pinocytosis assay}

Microglial pinocytosis was induced by ATP $\gamma \mathrm{S}$ as previously described (Li et al., 2013). Specifically, cells were incubated in MEM containing $0.1 \mathrm{~mm}$ $\mathrm{ATP} \gamma \mathrm{S}$ and different fluorescent probes (as indicated) at $37^{\circ} \mathrm{C}$ for $5 \mathrm{~min}$. After thorough washing with HBSS, cells were either directly used for live-cell imaging or fixed for immunostaining followed by microscopic analysis. Macrophage colony-stimulating factor (MCSF; $100 \mathrm{ng} / \mathrm{ml}$ ) was also used to induce microglial pinocytosis in both cultures and brain slices. The $\mathrm{pH}$ value within microglial pinosomes was evaluated with LysoSensor Yellow/Blue dextran (Invitrogen), which emits maximal fluorescence at $452 \mathrm{~nm}$ under neutral $\mathrm{pH}$ and exhibit maximal fluorescence at $521 \mathrm{~nm}$ under acidic condition. The ratio of the fluorescence intensity at $521 \mathrm{~nm}$ to the intensity at $452 \mathrm{~nm}$ thus indicates the $\mathrm{pH}$ value (Liu et al., 2011).

\section{Brain slice preparation}

CX3CR1 $1^{\mathrm{GFP} /+}$ mice (male, 2 weeks postnatal), with GFP expression cassette inserted in the CX3CR1 locus to specifically label microglia in the brain, were anesthetized with chloral hydrate, and perfused with ice-cold artificial CSF (aCSF) containing the following (in $\mathrm{mM}$ ): 110 choline chloride, $2.5 \mathrm{KCl}, 0.5 \mathrm{CaCl}_{2}, 7 \mathrm{MgCl}_{2}, 25 \mathrm{NaHCO}_{3}, 1.5 \mathrm{NaH}_{2} \mathrm{PO}_{4}$, and 10 glucose. Transverse slices $(200 \mu \mathrm{m})$ were cut on a tissue chopper (Microm $\mathrm{HM} 650 \mathrm{~V})$ and recovered in oxygenated $\left(95 \% \mathrm{O}_{2}\right.$ and $\left.5 \% \mathrm{CO}_{2}\right)$ aCSF containing the following (in mM): $125 \mathrm{NaCl}, 2.5 \mathrm{KCl}, 2 \mathrm{CaCl}_{2}, 1.3$ $\mathrm{MgCl}_{2}, 25 \mathrm{NaHCO}_{3}, 1.3 \mathrm{NaH}_{2} \mathrm{PO}_{4}$, and 10 glucose, for 30 min before pinosome induction and confocal live imaging.

\section{Electrotransfection of microglial cells}

Plasmids were transfected into primary cultured rat microglia using the Neon transfection system (Invitrogen) according to the manufacturer's instructions. After transfection, the cells were maintained in MEM containing $2 \%$ FBS for $12-24 \mathrm{~h}$ before further experiments.

\section{Lysosome labeling}

Lysosomes were labeled with LysoTracker or FM4-64 as previously reported (Zhang et al., 2007; Chazotte, 2011; Dou et al., 2012). Briefly, microglial cells were incubated in MEM containing $50 \mathrm{nM}$ LysoTracker for $1 \mathrm{~h}$ or $10 \mu \mathrm{M}$ FM4-64 for $2 \mathrm{~h}$. After thorough washing, cells were maintained in culture medium for another $30 \mathrm{~min}$ followed by the pinocytosis assay.

\section{Drug treatments}

The effects of protease inhibitors cocktail (1:200, P1860, Sigma-Aldrich) were assessed after $1 \mathrm{~h}$ preincubation. The mixture contains aprotinin, bestatin, E-64, leupeptin, and pepstatin A, and was pinocytosed with protein dyes, thus providing long-lasting inhibitory effect. The dynamin inhibitor, dynasore or Dynole-34-2, was used at a concentration of $40 \mu \mathrm{M}$ and required a preincubation period of $30 \mathrm{~min}$. Dynole-31-2, negative control for Dynole-34-2 was used at a concentration of $400 \mu \mathrm{M}$. The preincubation was usually followed by incubation with ATP $\gamma S$ and endocytic probes, with the relevant inhibitors still present.

\section{Immunostaining}

Cells pulse-chased with lysine-fixable dextrans were immunostained as described previously (Li et al., 2013). In brief, cells were fixed in $4 \%$ paraformaldehyde, washed with $0.1 \mathrm{M}$ PBS, and permeabilized with $0.1 \%$ saponin. After blocking in 10\% FBS/PBS, cells were incubated with primary antibodies diluted in $1 \%$ FBS, followed by detection using AlexaFluor-conjugated secondary antibodies (as indicated; 1:1000, Invitrogen).

\section{Magnetic bead-based isolation assay}

The isolation of ATP $\gamma \mathrm{S}$-induced pinosomes was achieved using iron oxide (II, III) magnetic nanoparticles (Sigma-Aldrich). Briefly, purified primary microglia were pulsed for 5 min with $100 \mu \mathrm{M}$ ATP $\gamma \mathrm{S}$ and 1 $\mathrm{mg} / \mathrm{ml}$ magnetic nanoparticles (average size, 5 or $20 \mathrm{~nm}$ in diameter), chased for $15 \mathrm{~min}$, and then homogenized. Cell nuclei and undisrupted cells were removed by centrifugation at $1200 \times g$ for $10 \mathrm{~min}$. The postnuclear extracts were placed on a magnet (IMagnet, BD Bioscience) for $30 \mathrm{~min}$ to separate the nonmagnetic (supernatant) and magnetic fractions. The magnetic fraction (on the tube wall) was resuspended as magnetic endosomes (MEs). The nonmagnetic fraction was centrifuged at $20,000 \times g$ for $30 \mathrm{~min}$ and the pellet was resuspended as crude endosomes (CEs). The resuspension buffer volume of ME:CE was 1:10. In the dynasore-treated group, $40 \mu \mathrm{M}$ dynasore was added during the pulsechase period. Cells treated with DMSO served as the solvent control. Protein lysates from MEs and CEs were separated on 12\% (w/v) SDSPAGE, transferred to PVDF membranes, and detected according to the standard method of ECL Western blotting (GE Healthcare).

\section{Transmission electron microscopy combined with} negative staining

MEs isolated from microglia pulse-labeled with 5 or $20 \mathrm{~nm}$ magnetic nanoparticles were loaded onto copper grids with a magnet underneath for $5 \mathrm{~min}$. Then the grids were washed with $0.1 \mathrm{M}$ PBS, and negatively stained with $1 \%$ phosphotungstic acid (PTA). In immunogold-labeling TEM, grids with isolated MEs were washed with $2.5 \% \mathrm{FBS}$ in $0.1 \mathrm{M}$ PBS. After blocking with 10\% FBS/PBS, grids were incubated in rabbit antiMHC II pAb dissolved in 1\% FBS/PBS (1:200), and then incubated in 5 $\mathrm{nm}$ nanogold-labeled anti-rabbit secondary antibody (1:100), followed by negative staining with $1 \%$ PTA. Samples were observed with an H-7650 transmission electron microscope (Hitachi) using an accelerating voltage of $80 \mathrm{kV}$ and images were obtained with a model $830 \mathrm{CCD}$ camera (Gatan).

\section{Cell-free in vitro sorting assay}

The dextran-labeled pinosomes were prepared according to the description in the magnetic endosome isolation assay with minor modifications. In brief, microglial cells were incubated with $100 \mu \mathrm{M}$ ATP $\gamma \mathrm{S}$, $1 \mathrm{mg} / \mathrm{ml}$ magnetic nanoparticles (20 nm average diameter), as well as fluorescence-linked dextrans for $5 \mathrm{~min}$, washed, and immediately homogenized. The magnetic endosomes were isolated by a magnet and then resuspended in homogenization buffer ( $250 \mathrm{~mm}$ sucrose, $3 \mathrm{~mm}$ imidazole, and $\mathrm{HCl}, \mathrm{pH}$ 7.4) with protease inhibitors (1 mM PMSF and 1\% protease inhibitor cocktail). 
Crude rat-brain cytosol was prepared according to previous studies (Barysch et al., 2010) with a few modifications. Briefly, adult SpragueDawley rat brains were homogenized in $60 \%(\mathrm{v} / \mathrm{w})$ homogenization buffer with protease inhibitors. The crude cytosol was obtained by centrifugation at $2000 \times g$ for $15 \mathrm{~min}$, followed by centrifugation at $12,000 \times g$ for $30 \mathrm{~min}$, and preserved at $-80^{\circ} \mathrm{C}$ before use.

The reaction mixture $(50 \mu \mathrm{l})$ contained magnetic pinosomes, $5 \mathrm{mg} / \mathrm{ml}$ crude rat brain cytosol, and the ATP regeneration system (Rong et al., 2012). The ATP regeneration system was composed of 11.25 mM HEPES, $1.35 \mathrm{~mm}$ magnesium acetate, $0.18 \mathrm{~mm}$ DTT, $45 \mathrm{~mm}$ potassium acetate, 1 mM GTP, $3.2 \mathrm{~mm}$ ATP, $26 \mathrm{~mm}$ creatine phosphate, and $0.132 \mathrm{mg}$ of creatine kinase. The reaction mixture was added to a glass-bottomed dish and placed on the IMagnet for $5 \mathrm{~min}$, allowing the pinosomes to settle to the bottom. Time-lapse images were obtained using a confocal microscope (FV500; Olympus) with a 1.2 NA $60 \times$ water objective. For immunodepletion studies, rabbit anti-dynamin2 (Abcam), mouse anti-VAMP7 (Abcam), rabbit anti-syntaxin8 (Abcam), mouse antiSNAP25 (Millipore), and rabbit anti-SNAP23 (Synaptic Systems) were added at a dilution of 1:25.

\section{Determination of antigen presentation efficiency}

Mouse microglia culture. Primary mouse microglia were cultured mainly according to the primary rat microglia culture procedure with a few modifications. A mixed glial culture was prepared from the cerebral cortex of neonatal C57BL/6 mice and maintained for a longer period (14-16 d) before microglial cell harvest. Upon harvest, microglial cells were plated in a 96-well plate at $1 \times 10^{5}$ cells/well and maintained for $12-16 \mathrm{~h}$ before further experiments.

OT-II CD4 T cell isolation. Lymphocytes were isolated from the spleen of 6- to 8-week-old male OT-II transgenic mice as described previously (Wang et al., 2012). CD4 + T cells were purified with mouse CD4+ T-lymphocyte enrichment set-DM (BD Biosciences) following the manual.

$T$ cell proliferation assay. T cell proliferation was assessed with a CellTrace CFSE cell proliferation kit (Invitrogen) according to the manual. Carboxyfluorescein succinimidyl amino ester (CFSE) is a membranepermeable dye that binds to intracellular proteins once inside the cells and is successively halved in cell division, thus serving as an indicator of cell proliferation. Purified CD4 + T cells were loaded with $1 \mu \mathrm{M}$ CFSE for $2 \mathrm{~min}$. After thorough washing, cells were maintained in RPMI1640 medium containing 10\% FBS before coculture with microglia.

Antigen presentation assay. Primary mouse microglia in 96-well plates were incubated in MEM containing $0.1 \mathrm{~mm} \mathrm{ATP} \gamma \mathrm{S}$ and the indicated antigens, as well as $40 \mu \mathrm{M}$ dynasore or DMSO (control group) for $5 \mathrm{~min}$. Different antigens were used for different groups: $5 \mathrm{mg} / \mathrm{ml}$ ovalbumin (OVA), $0.5 \mathrm{mg} / \mathrm{ml}$ OVA (323-339) peptide, $5 \mathrm{mg} / \mathrm{ml}$ OVA with 0.5 $\mathrm{mg} / \mathrm{ml}$ OVA (323-339) peptide, or nothing (as basal). After thorough washing, cells were incubated in MEM with $10 \%$ FBS together with $40 \mu \mathrm{M}$ dynasore or DMSO for a further $2 \mathrm{~h}$ before coculture with T cells. OT-II CD4 + T cells $\left(5 \times 10^{5}\right)$ were added into each well, and the medium was replaced with RPMI 140 containing 10\% FBS. The microglia and T cells were cocultured for another $72 \mathrm{~h}$ before T-cell activity and proliferation were assessed. The activity was determined by the IFN- $\gamma$ concentration in the medium with a mouse IFN- $\gamma$ immunoassay kit (R\&D Systems), whereas the proliferation was measured by the dilution of CFSE intensity using a flow cytometer (BD Biosciences).

\section{Determination of microglial activation}

Primary cultured mouse microglia were untreated (as basal) or treated with $5 \mathrm{mg} / \mathrm{ml}$ OVA in the presence of $40 \mu \mathrm{M}$ dynasore or DMSO (as the solvent control) for $72 \mathrm{~h}$. The surface expression of MHC I, MHC II, CD80, and CD86 was detected by flow cytometry.

\section{Determination of protein hydrolysis}

Primary cultured rat microglia were pretreated with $40 \mu \mathrm{M}$ dynasore or DMSO (control), then pulse-labeled with $2 \mathrm{mg} / \mathrm{ml}$ DQ-OVA, a selfquenched conjugate of ovalbumin that exhibits bright green fluorescence upon proteolytic degradation. After thorough washing, the cells were scanned with a laser confocal microscope. The increase of fluorescent intensity represents the degree of protein hydrolysis.

\section{Image acquisition and analysis}

Confocal live-cell imaging was performed on an Olympus FV1k2 confocal microscope with a $60 \times /$ NA1.2 water objective. Cells were incubated in L-15 medium on a temperature-controlled stage heater set at $37^{\circ} \mathrm{C}$. Images of immunostained samples were obtained using a Zeiss LSM510 confocal microscope with a $63 \times / \mathrm{NA1} 1.4$ oil-objective or a Nikon A1 confocal microscope with a $60 \times / \mathrm{NA} 1.25$ oil-objective. Image analysis was performed with Image Pro Plus 6.1 (Media Cybernetics), and AutoQuant X4 (Media Cybernetics).

In live-imaging experiments, the fluorescence intensity of the indicated dyes in pinosomes (FIP) and the fluorescence intensity of the whole-cell (FIW) were measured separately. The escaping rate of the indicated dye within 15 min was defined as follows:

$$
\left(D_{\text {dye }}\right)=\frac{\frac{F I P_{0 \min }}{F I W_{0 \mathrm{~min}}}-\frac{F I P_{15 \mathrm{~min}}}{F I W_{15 \mathrm{~min}}}}{\frac{F I P_{0 \mathrm{~min}}}{F I W_{0 \mathrm{~min}}}} .
$$

The translocation selectivity of two fluorescent probes was defined as the ratio of the escaping rate of the two probes $\left(R_{\text {dye 1/dye } 2}=\frac{D_{\text {dye } 1}}{D_{\text {dye } 2}}\right)$. For example, as shown in Figure $2 F, R_{T D 3 S / F D 3 S}=\frac{D_{T D 3 S}}{D_{F D 3 S}}$.

The colocalization rate $(\mathrm{C})$ was defined as follows:

$$
C_{1}=\frac{\sum_{i} S 1_{i, \text { coloc }}}{\sum_{i} S 1_{i}},
$$

where $S 1_{i, \text { coloc }}=S 1_{i}$ if $S 2_{i}$ is within thresholds, $S 1_{i, \text { coloc }}=0$ if $S 2_{i}$ is outside the threshold levels. $\mathrm{S} 1$ and $\mathrm{S} 2$ indicate the signal intensity of pixels in the first and second channel, respectively.

\section{Statistical analyses}

Statistical analysis was performed with SAS software (Statistical Analysis System, SAS Institute). Data are presented as mean \pm SEM. Statistical comparisons were assessed by one-way ANOVA with Tukey's test.

\section{Results}

\section{Rapid protein hydrolysis and selective escape of small} peptides from pinosomes

To determine whether engulfed soluble contents are selectively delivered, we induced pinocytosis in cultured microglia with ATP $\gamma \mathrm{S}$ for $5 \mathrm{~min}$ and dual-labeled the pinosomes with fluorescence-conjugated ovalbumin and dextran, an established polysaccharide marker of pinocytosis (Chazotte, 2009), followed by confocal live imaging. Soon after internalization, TR-OVA [Texas Red-ovalbumin with an approximate molecular weight (MW) of $45 \mathrm{kDa}$ ] and FD70S (fluorescein-dextran; average MW $70 \mathrm{kDa}$ ) were nonselectively engulfed into the same pinosomes (Fig. 1A). However, TR-OVA was gradually escaped from the pinosomes 10 min after loading, whereas FD70S was still retained inside (Fig. 1 B, C). Replacing TR-OVA with tetramethylrhodamine-conjugated OVA323-339 peptide (323-339 aa of OVA) also resulted in escape of OVA peptides and retention of the FD70S 10 min after loading (Fig. 1D). Surprisingly, treatment of cells with protease inhibitors prevented the escape of TR-OVA proteins but not that of OVA peptides (Fig. $1 E-G$ ). These results indicate that large proteins are degraded in pinosomes into small peptides, which are then selectively delivered out of pinosomes.

The proteolytic function of pinosomes was further verified by dual-loading microglial pinosomes with TD70S (Texas Reddextran, $70 \mathrm{kDa}$ ) and a self-quenching conjugate of OVA, DQovalbumin (DQ-OVA), which emits bright green fluorescence upon proteolytic degradation. A marked increase of the fluores- 
A

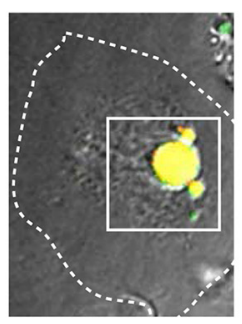

B

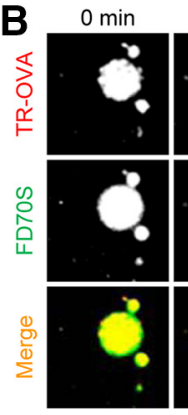

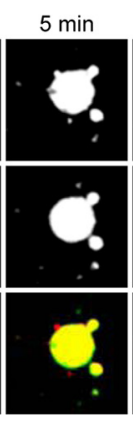

E

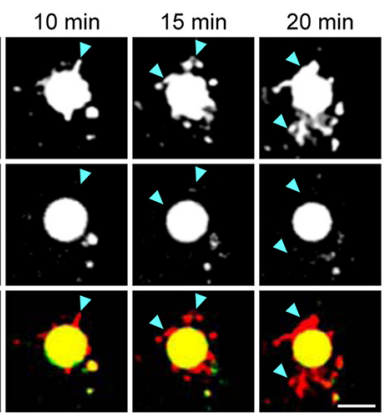

Protease Inhibitor

D
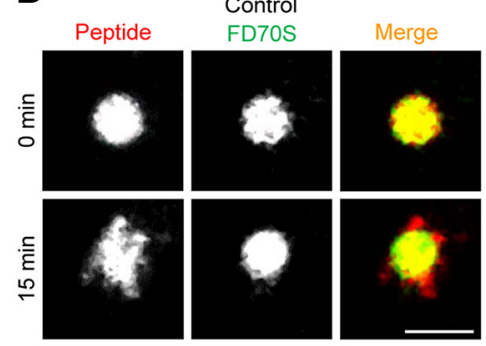

G

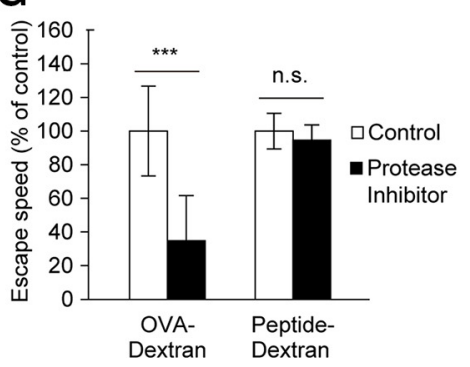

J

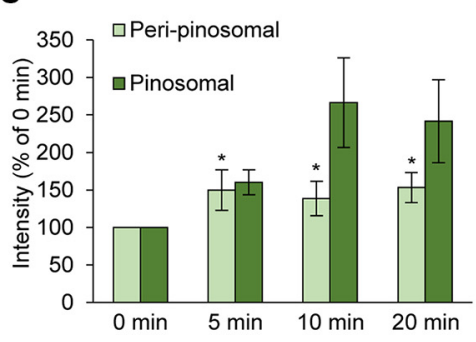

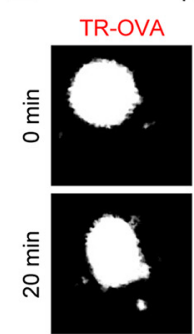
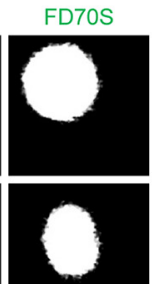

H

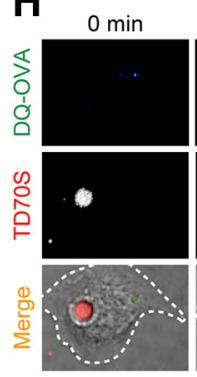

K

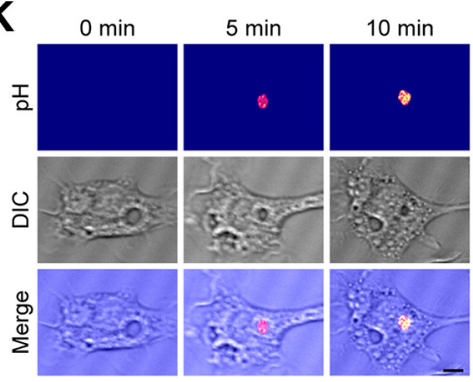

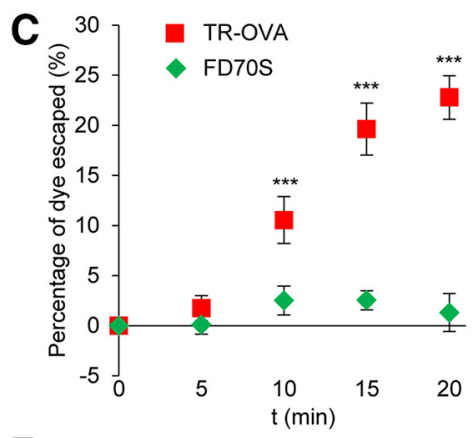

F

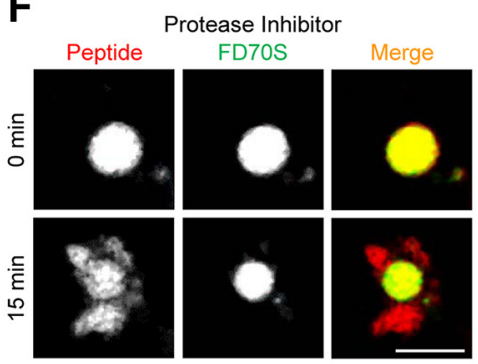

I

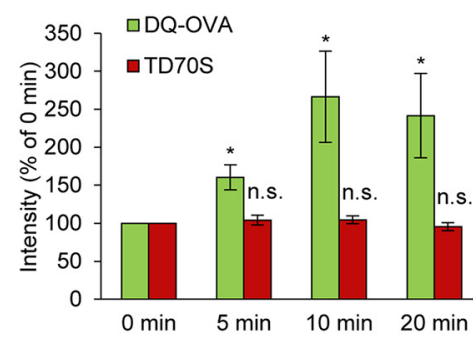

L

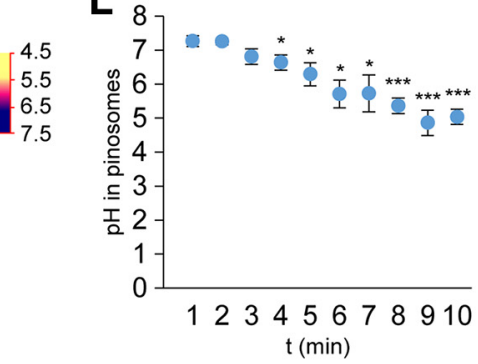

Figure 1. Selective delivery of contents and proteolytic function in pinosomal lumen. $\boldsymbol{A}, \boldsymbol{B}$, Live imaging of a typical microglial pinosome pulse-labeled with TR-OVA (Texas Red-ovalbumin, red) and FD70S (fluorescein-dextran, $70 \mathrm{kDa}$; green). Cells were pretreated with DMSO. Time-sequence images in $\boldsymbol{B}$ show the boxed area of $A$. Dotted lines outline the cell. Arrowheads indicate the TR-0VA that diffused out of the pinosome. Scale bar, $5 \mu \mathrm{m}$. $\boldsymbol{C}$, Quantitative data of $\boldsymbol{B}$ summarizing the cumulative percentages of TR-OVA or FD70S that escaped from the pinosomes. $\boldsymbol{D}-\boldsymbol{F}$, Live imaging of typical pinosomes pulse-labeled with TR-OVA ( $\boldsymbol{E}$, red) or TAMRA-0VA (323-339) peptides ( $\boldsymbol{D}, \boldsymbol{F}$; red), as well as FD70S (green). Cells were pretreated with DMSO (control, $\boldsymbol{D}$ ) or protease inhibitors $(\boldsymbol{E}, \boldsymbol{F})$. Scale bars, $5 \mu \mathrm{m}$. G, Quantitative data showing the effect of protease inhibitor on the escape of OVA-protein or OVA-peptides from pinosomes (data from 4 independent experiments). $\boldsymbol{H}$, Time-sequence images of a microglial cell pulse-labeled with DQ-OVA (green) and TD70S (red). Dotted lines outline the cell. Scale bar, $5 \mu \mathrm{m}$. $I$, Quantitative data summarizing the fluorescence intensity of DQ-OVA or TD70S in pinosomes. $J$, Quantitative data summarizing the fluorescence intensity of DQ-0VA inside (pinosomal) or outside (peripinosomal) the pinosomes $\left({ }^{*} p<0.05\right.$ compared with $0 \mathrm{~min}$; data from 4 independent experiments). $\boldsymbol{K}$, Pinosomal $\mathrm{pH}$ values were measured ratiometrically using LysoSensor Yellow/Blue dextran. Time-sequence $\mathrm{pH}$ changes are shown in pseudocolor. Scale bar, $5 \mu \mathrm{m}$. L, Quantitative data showing the pH value changes in pinosomes. Data show mean \pm SEM from three independent experiments unless otherwise specified (*** $p<$ $0.001,{ }^{* *} p<0.01,{ }^{*} p<0.05$; ANOVA with Tukey's test).

cence signal of DQ-OVA but not TD70S was observed inside pinosomes 10 min after loading (Fig. $1 H-J$ ), confirming the proteolytic ability of the pinosomes before the selective escape. Proteolysis requires an acidic environment; we thus evaluated the $\mathrm{pH}$ changes within pinosomal lumen using LysoSensor Yellow/Blue dextran, which emits blue fluorescence $(451 \mathrm{~nm})$ in neutral $\mathrm{pH}$ but green fluorescence $(521 \mathrm{~nm})$ in acidic conditions. We found that pinosomes undergo a dramatic acidification upon pinocytosis, with the luminal $\mathrm{pH}$ rapidly dropped from $7.27 \pm 0.15$ to $5.04 \pm 0.22$ within $10 \mathrm{~min}$ (Fig. $1 \mathrm{~K}, L$ ), indicating an appropriate environment in the pinosomal lumen for protein degradation. Together, these results indicated that small peptides and large proteins in pinosomal lumen have differential intracellular trafficking fates, likely resulting from the difference in their sizes.

Size-dependent trafficking of pinosomal luminal contents To further examine whether pinosomal luminal contents are selectively delivered based on their molecular sizes, we loaded microglial pinosomes with nondegradable luminal contents, FD70S and TD3S (Texas Red-dextran, $3 \mathrm{kDa}$ ), which are similar in the 

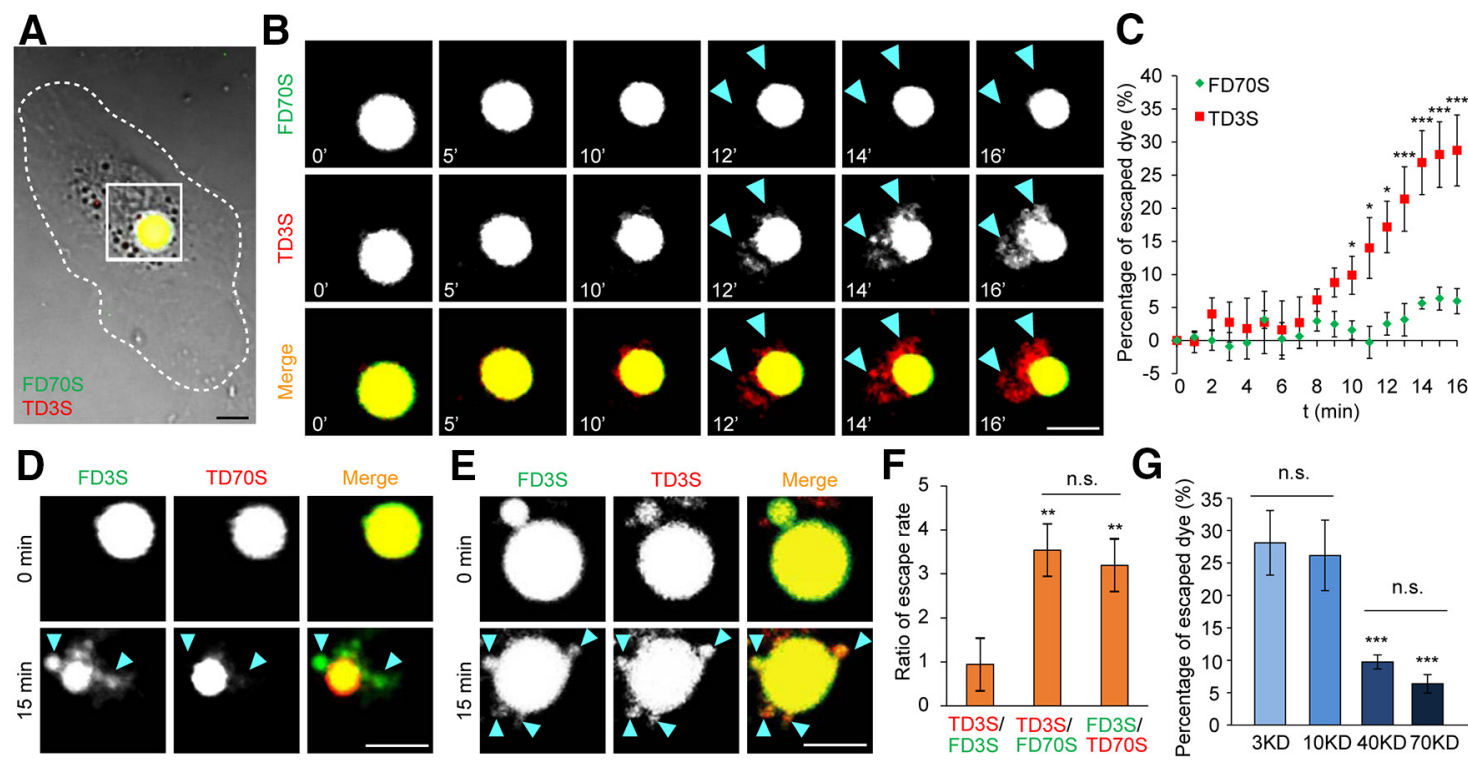

E
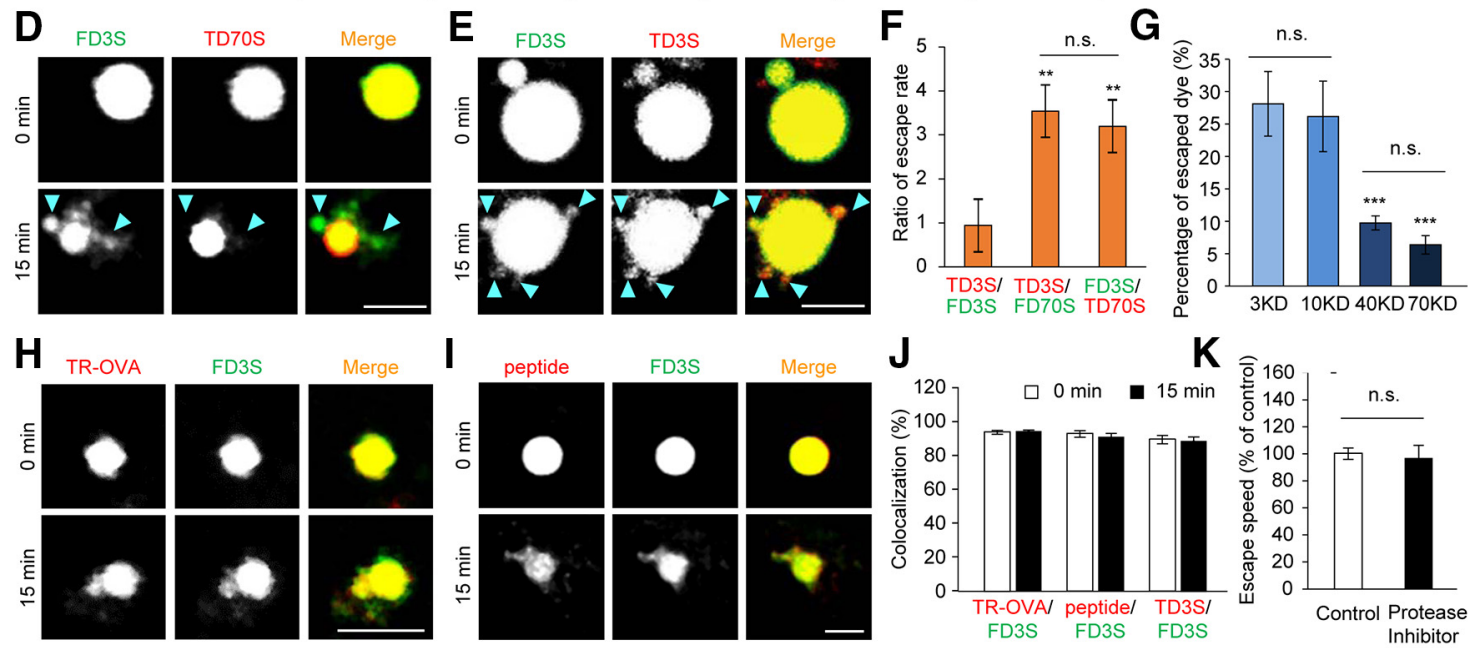

K

$\mathbf{L}$
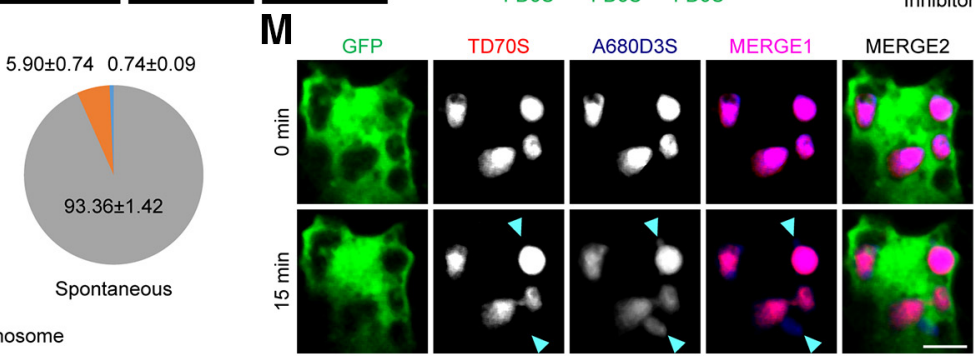

Figure 2. Size-based sorting of pinosomal luminal contents. $\boldsymbol{A}, \boldsymbol{B}$, Live imaging of a typical microglial pinosome pulse-labeled with FD70S (fluorescein-dextran, $70 \mathrm{kDa}$; green) and TD3S (Texas Red-dextran, $3 \mathrm{kDa}$; red). Time-sequence images in $\boldsymbol{B}$ show the boxed area of $\boldsymbol{A}$. Dotted lines outline the cell. Arrowheads indicate the TD3S that diffused out of the pinosome. Scale bar, $5 \mu \mathrm{m}$. $\boldsymbol{C}$, Quantitative data of $\boldsymbol{B}$ summarizing the cumulative percentages of $F D 70 S$ or TD3S that diffused out of the pinosomes. $\boldsymbol{D}, \boldsymbol{E}$, Time-sequence images of pinosomes in microglia pulse-labeled with pairs of dextrans: FD3S/TD70S (D) and FD3S/TD3S (E). Arrowheads indicate escaped dextrans. Scale bars, $5 \mu \mathrm{m}$. $\boldsymbol{F}$, Quantitative data summarizing the ratio of the diffusion rate of indicated pairs of dyes in $15 \mathrm{~min}$. G, Quantitative data summarizing the escaping rate of molecules with different sizes in $15 \mathrm{~min}$. Time-sequence images of a typical microglial pinosome pulse-labeled with TR-OVA (red, $\boldsymbol{H}$ ) or OVA peptide (red, $\boldsymbol{I}$ ), as well as FD3S (fluorescein-dextran, $3 \mathrm{kDa}$; green). Scale bar, $5 \mu \mathrm{m}$. $\boldsymbol{J}$, Quantitative data of $(\boldsymbol{E}, \boldsymbol{H}, \boldsymbol{I})$ summarizing the colocalization ratio of TR-0VA, OVA peptide or TD3S with FD3S immediately or 15 min after labeling (data from 4 independent experiments). $\boldsymbol{K}$, Quantitative data showing the effect of protease inhibitor on escape of TD3S from pinosomes (data from 4 independent experiments). L, Quantitative data summarizing the effects of ATP $\gamma S$ and MCSF on macropinocytosis and size-based sorting. $M$, Time-sequence images of a typical GFP + microglia in a brain slice from CX3CR ${ }^{\text {GFP/+ }}$ mouse. Pinosomes were induced by MCSF and labeled with TD70S (red) and A680D3S (AlexaFluor 680-dextran, $3 \mathrm{kDa}$, blue) simultaneously. Scale bar, $5 \mu \mathrm{m}$. Data show mean \pm SEM from three independent experiments unless otherwise specified $\left({ }^{* * *} p<0.001\right.$, ${ }^{* *} p<0.01,{ }^{*} p<0.05$; ANOVA with Tukey's test).

sizes with OVA ( $45 \mathrm{kDa})$ and OVA peptide $(2 \mathrm{kDa})$, respectively. Both dextrans were evenly engulfed and completely colocalized within the pinosomes immediately after loading (Fig. 2A). Nine minutes later, however, TD3S began to escape from the pinosomes while FD70S remained inside (Fig. $2 B, C$ ), similar to the selective escape of TR-OVA as shown in Figure $1 B$.

The two dextrans, FD70S and TD3S, differ both in size and conjugated fluorophore. To determine which of these contributed to the differential intracellular trafficking, we labeled the pinosomes using dextrans with switched fluorophores, i.e., TD3S/FD3S or TD70S/FD3S, and observed the same escape of the smaller dextran $(3 \mathrm{kDa})$ but retention of the larger one $(70$ kDa; Fig. 2D-F). Moreover, the two small dextrans, TD3S and FD3S, had similar escaping speed and displayed an identical dis- tribution after escaping from pinosomes (Fig. $2 F, J$ ). Assessment of intracellular trafficking of dextrans revealed that the escaping speed of $10 \mathrm{kDa}$ dextran was similar to that of $3 \mathrm{kDa}$ dextran, whereas 40 and $70 \mathrm{kDa}$ dextrans have similar escaping speed (Fig. $2 G$ ). Furthermore, TR-OVA or OVA peptide also distributed in the same compartments with FD3S 15 min after induction of engulfment (Fig. $2 H-J$ ), indicating the same selective delivery mechanism for degraded protein, peptide, and small size-dextrans. We further confirmed that the size-based sorting of dextrans was not affected by the protease inhibitor cocktail (Fig. $2 K$ ), which effectively blocked the escape of pinocytosed TR-OVA but not OVA peptide (Fig. 1E$G)$. Altogether, our results demonstrated that the differential escape of proteins and peptides showed in Figure 1 was mediated by a sizebased sorting mechanism. 


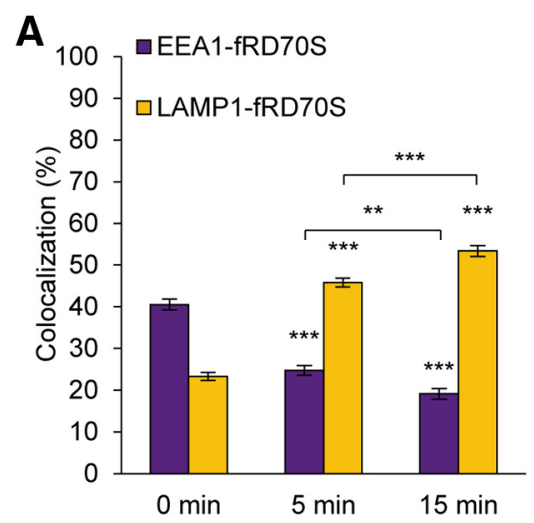

C

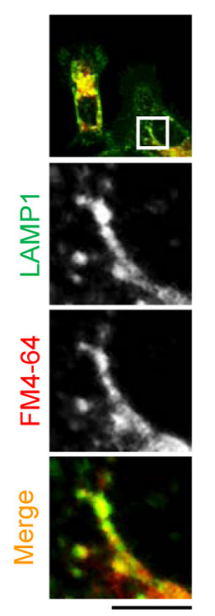

D

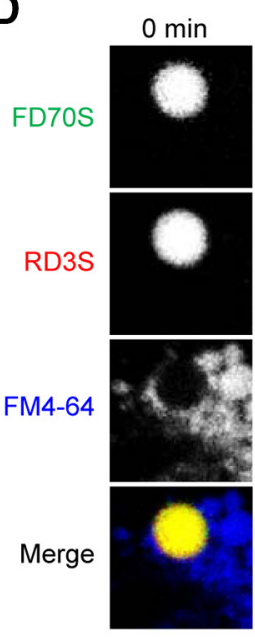

B

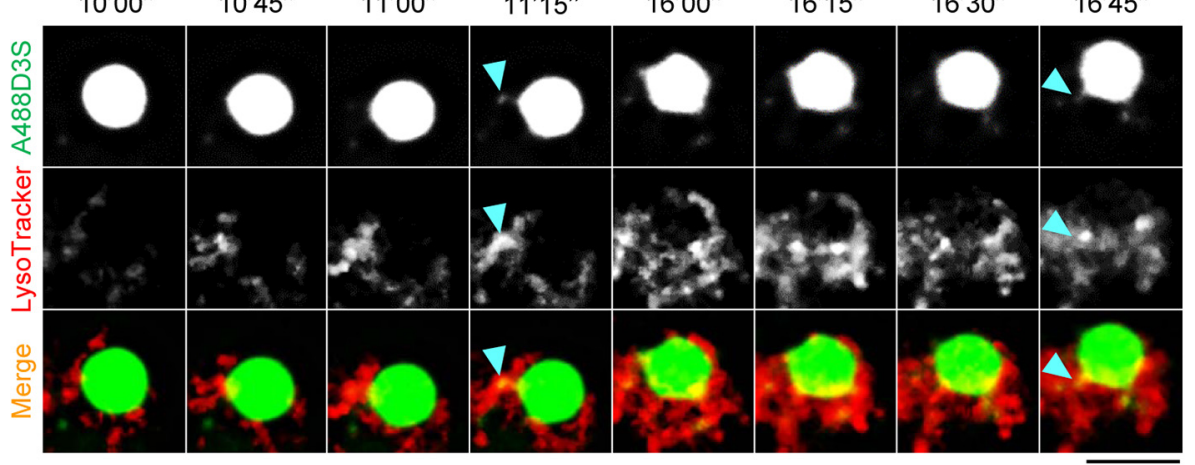

8 min

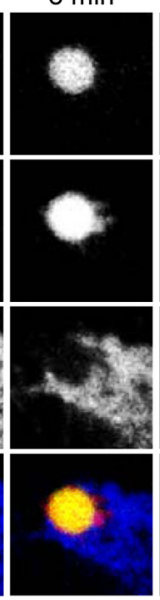

$10 \mathrm{~min}$

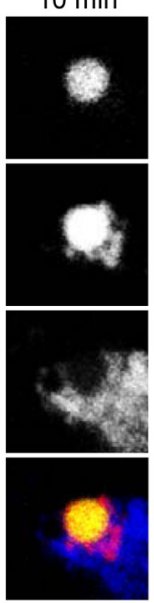

$12 \mathrm{~min}$

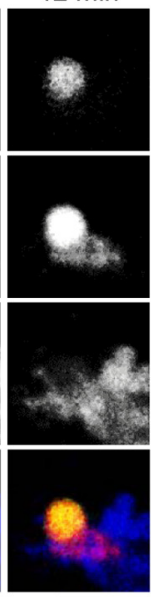

E

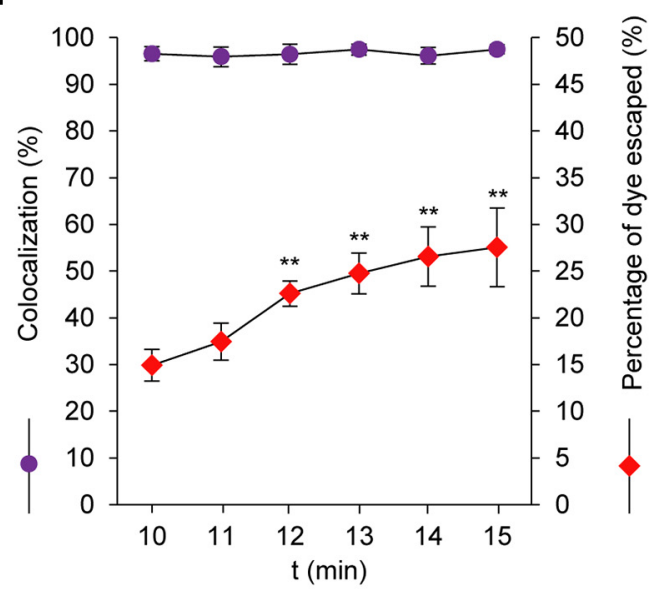

$\mathbf{F}$

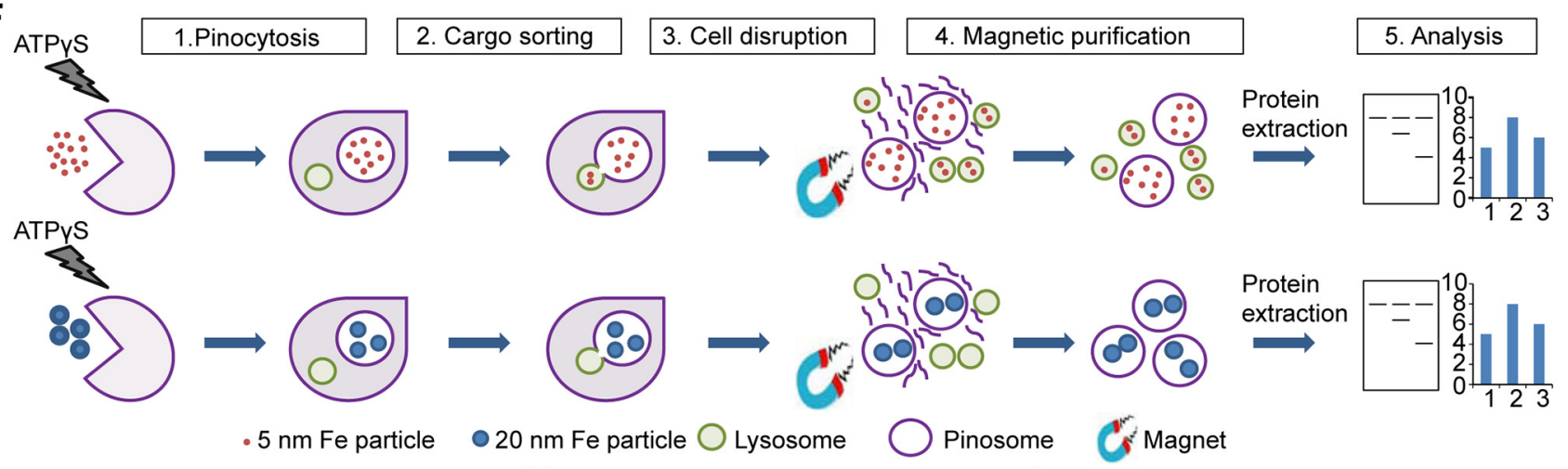

G

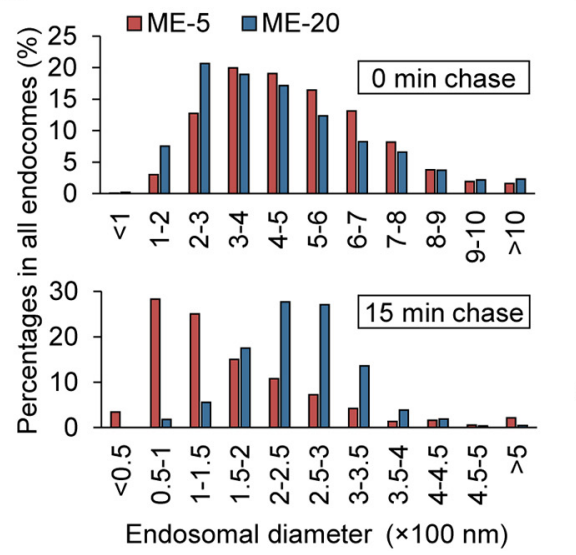

H

Beads size $5 \mathrm{~nm} 20 \mathrm{~nm} 5 \mathrm{~nm} 20 \mathrm{~nm}$

LAMP1

cathepsin D

Rab7

Rab5

J

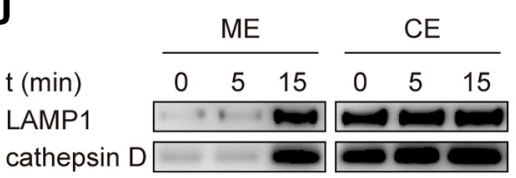

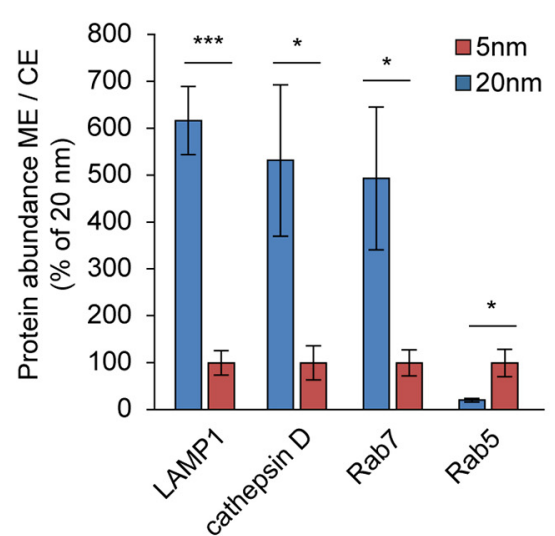

Figure 3. Identification of the target compartment of the size-based sorting. A, Quantitative data summarizing the colocalization rate of fRD70S (lysine-fixable tetramethylrhodamine-dextran, $70 \mathrm{kDa}$ ) with EEA1 (purple) or with LAMP1 (yellow). LAMP1 and EEA1 were detected by immunofluorescence in microglia pulse-labeled with fRD70S and (Figure legend continues.) 
A
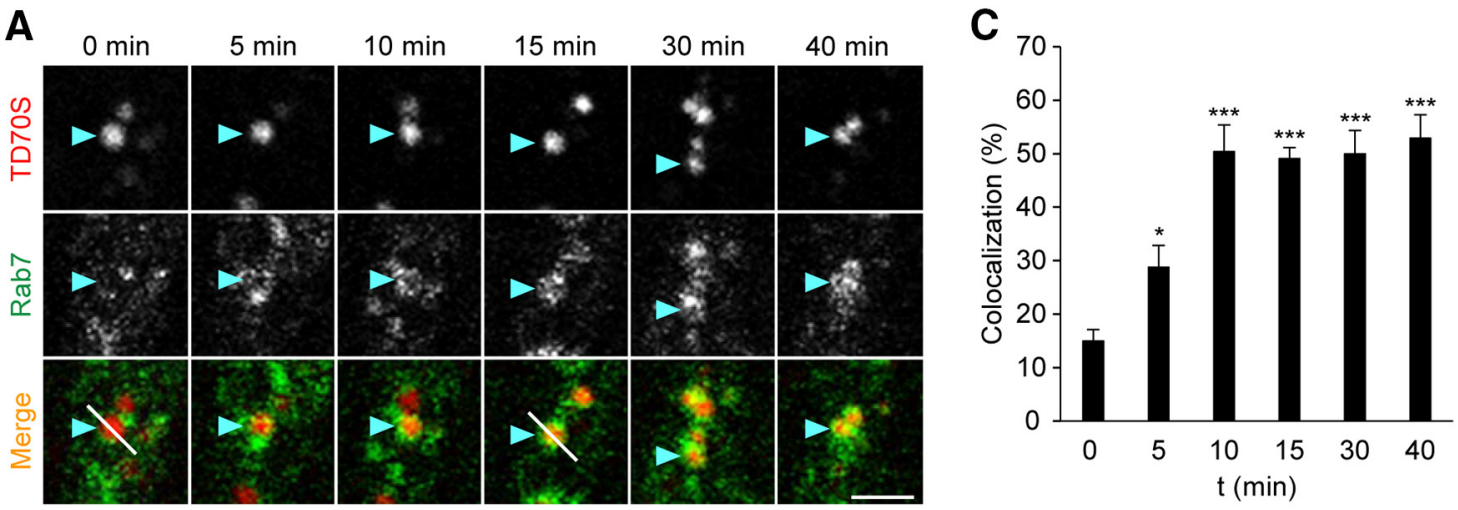

B
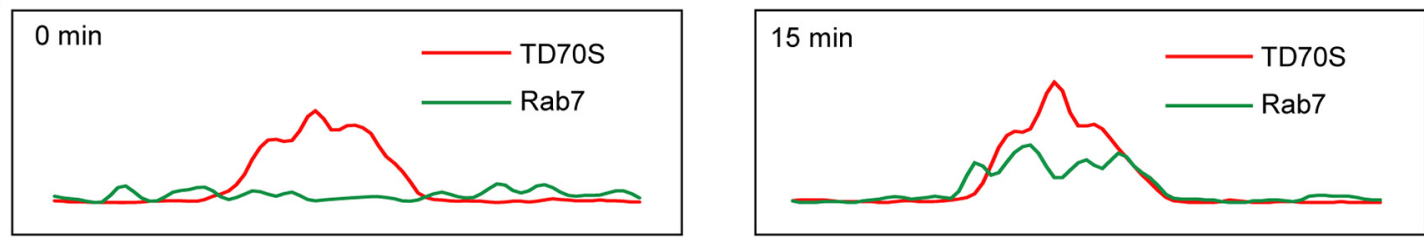

D
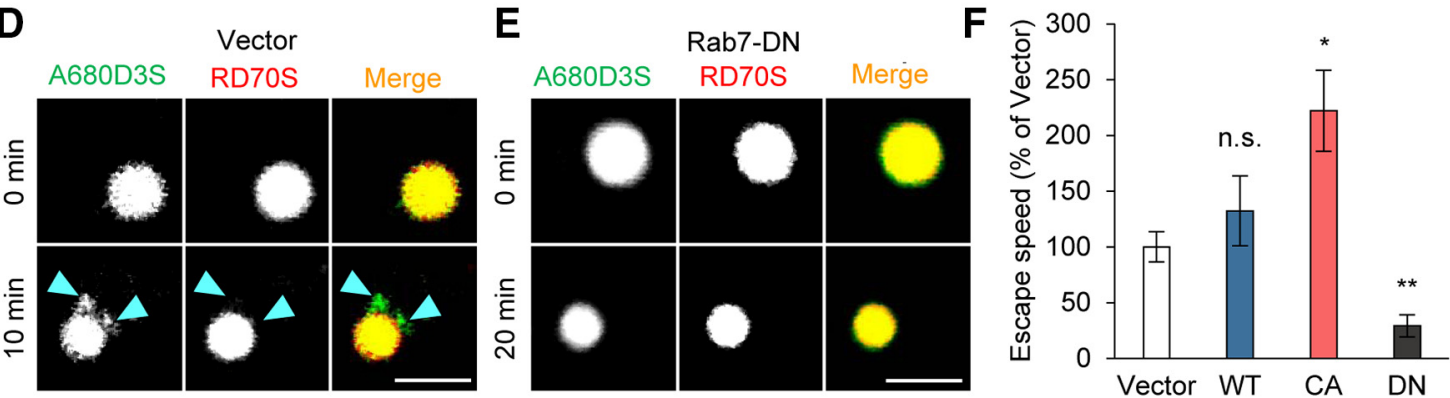

Figure 4. Function of Rab7 in the size-based sorting. $\boldsymbol{A}$, Time-sequence images of several pinosomes in microglia transfected with Rab7-EGFP plasmids and pulse-loaded with TD70S. Rab7 (green) was recruited to the TD70S-labeled pinosomes (red) in minutes and retained on them for at least $30 \mathrm{~min}$. Arrowheads indicate the same TD70S-labeled pinosome. Scale bar, $5 \mu \boldsymbol{m}$. $\boldsymbol{B}$, Fluorescence intensity profiles of a set of pixels distributed on the white lines drawn across the pinosome shown in $\boldsymbol{A}$. The emission wavelengths corresponding to Rab7-EGFP (green) and TD70S (red) are plotted. Data are presented as arbitrary units versus the length of the white line. C, Quantitative data summarizing the colocalization rate of Rab7 and TD70S-labeled pinosomes. $\boldsymbol{D}$, $\boldsymbol{E}$, Time-sequence images of a typical pinosome in microglia transfected with dominant-negative Rab7 plasmids (Rab7-DN, $\boldsymbol{E}$ ) or empty vector (D). Cells were pulse-labeled with RD70S (tetramethylrhodamine-dextran, $70 \mathrm{kDa}$ ) and A680D3S (AlexaFluor 680-dextran, $3 \mathrm{kDa}$ ) and chased for the indicated times. Arrowheads indicate A680D3S (green) that diffused out of the RD70S-labeled pinosome (red). Scale bars, $5 \mu \mathrm{m}$. F, Quantitative data showing the ratio of the diffusion rate of A680D3S to that of RD70S in 15 min. Cells were transfected with empty vector (Vector), wild-type Rab7 (WT), the constitutively active form (CA), or the dominant-negative (DN) form of Rab7. Values were normalized to the results from microglia transfected with empty vector (data from 5 independent experiments). Data show mean \pm SEM from three independent experiments unless otherwise specified $\left({ }^{* *} p<0.01 ;{ }^{*} p<0.05 ;\right.$ ANOVA with Tukey's test).

\section{$\leftarrow$}

(Figure legend continued.) chased for the indicated periods before fixation. $\boldsymbol{B}$, Live imaging of a microglial cell prelabeled with LysoTracker (red) and subsequently pulse-labeled with A488D3S (AlexaFluor 488-dextran, 3 kDa; green). Arrowheads indicate that dextran diffusing out of pinosomes colocalized with LysoTracker-preloaded lysosomes. Scale bar, $5 \mu \mathrm{m}$. C, Live imaging of a microglial cell transfected with LAMP1-GFP and labeled with FM4-64, showing the colocalization of FM4-64 (red) and LAMP1 (green). Bottom show the boxed area of the top panel. Scale bar, $5 \mu \mathrm{m}$. D, Live imaging of a microglial cell prelabeled with FM4-64 (blue) and subsequently pulse-labeled with FD70S (green) and RD3S (tetramethylrhodamine-dextran, 3 $\mathrm{kDa}$; red). Scale bar, $5 \mu \mathrm{m}$. $\boldsymbol{E}$, Quantitative data of $\boldsymbol{D}$. Left axis (purple circles) displays the colocalization rate of escaped RD3S and FM4-64. Right axis (red diamonds) displays the percentage of RD3S that escaped from the pinosomes (data from 5 independent experiments). $\boldsymbol{F}$, Diagram of the magnetic bead-based isolation assay. $G$, Quantitative data showing the diameter distribution of ME-5 (red column) and ME-20 (blue column) endosomes with (bottom panel) or without (top panel) a 15 min chase. $\boldsymbol{H}$, Western blots for LAMP1, cathepsin D, Rab7, and Rab5 in protein lysates harvested from MEs or CEs. I, Quantitative data of $\boldsymbol{H}$. The protein abundance of ME/CE was normalized to the result from the ME-20-treated group (data from 5 independent experiments). J, Western blots for LAMP1 and cathepsin D in protein lysates harvested from MEs and CEs. Cells were pulse-loaded with $5 \mathrm{~nm}$ magnetic beads and chased for the indicated time. Data show mean \pm SEM from three independent experiments unless otherwise specified ( ${ }^{* * *} p<0.001,{ }^{* *} p<0.01,{ }^{*} p<0.05$; ANOVA with Tukey's test).
To determine whether the size-dependent sorting occurs in a general manner within microglial macropinosomes, we analyzed the sorting in microglia with spontaneous and MCSF-induced pinocytosis. We found that the sorting occurs at a similar rate in spontaneous, ATP $\gamma S$ - or MCSF-induced pinosomes within 15 min (Fig. 2L). Importantly, size-based sorting was also observed in microglial cells in acute brain slices from CX3CR $1^{\mathrm{GFP} /+}$ mice (Fig. 2M), indicating that the sorting is not due to the artificial effect of cell culture system. These results suggested that the sizebased sorting is a general mechanism for selective trafficking of pinosomal contents.

Size-selective delivery of smaller contents to lysosomes Pinosomes undergo a maturation process from early to late forms (Racoosin and Swanson, 1993; Kerr et al., 2006). To characterize the nature of the pinosomes during sorting, ATP $\gamma S$-induced pinosomes were loaded with fRD70S (lysine-fixable tetramethylrhodamine-dextran, $70 \mathrm{kDa}$ ), followed by immunostaining with an early endosome marker (EEA1) and a late endosome/lysosome marker (LAMP1). Immediately after loading, the fRD70Slabeled pinosomes were mainly colocalized with EEA1. After 5 


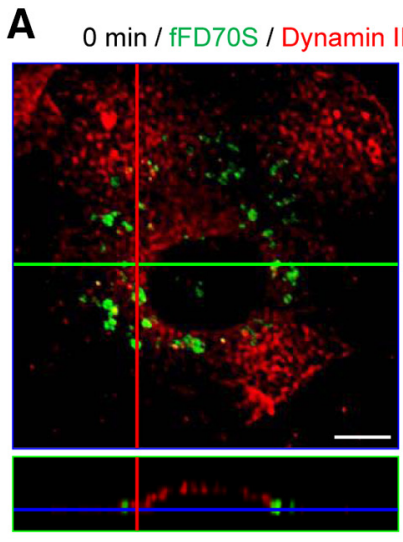

C

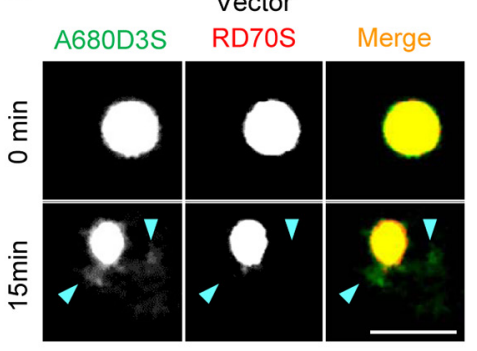

F

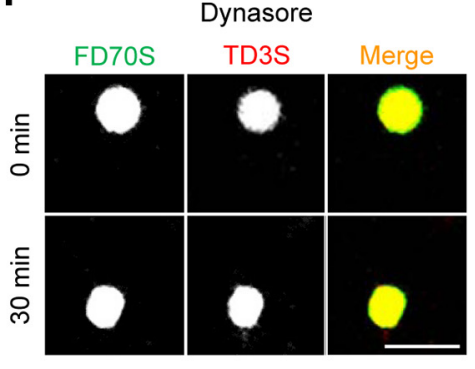

I

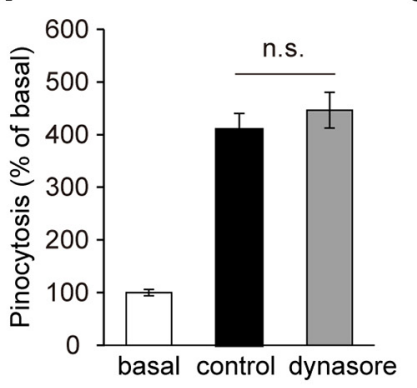

L

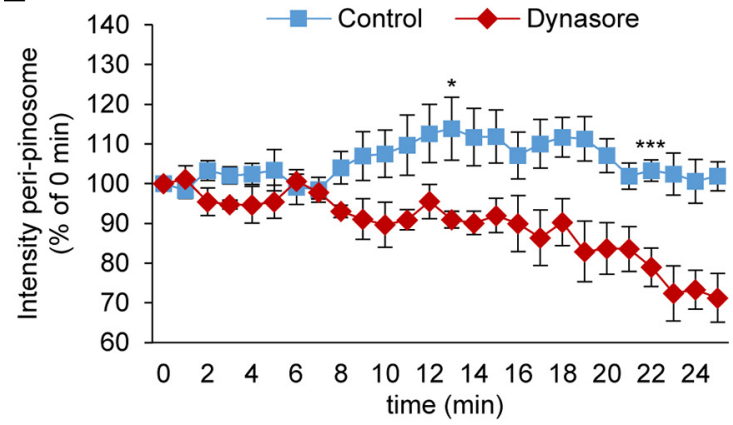

20 min / fFD70S / Dynamin II
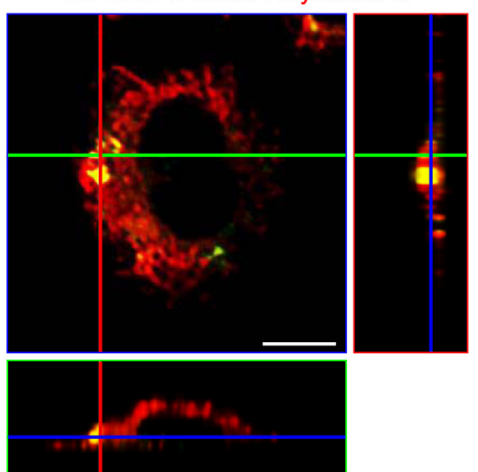

D

Dynamin II - DN

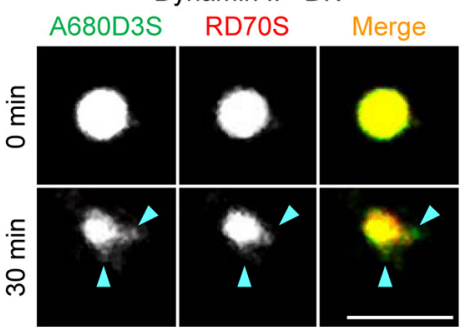

G

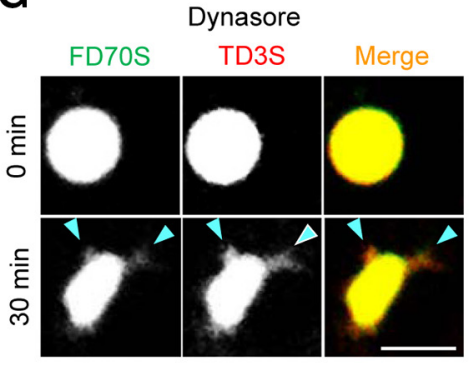

J

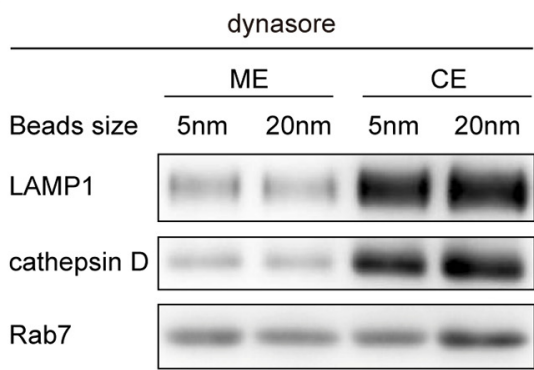

B

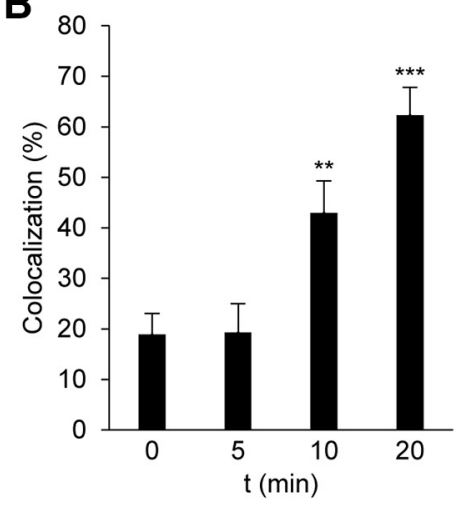

E

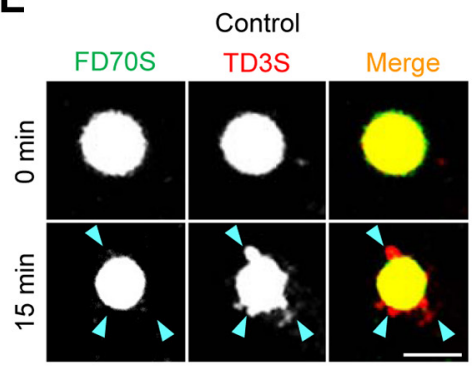

H

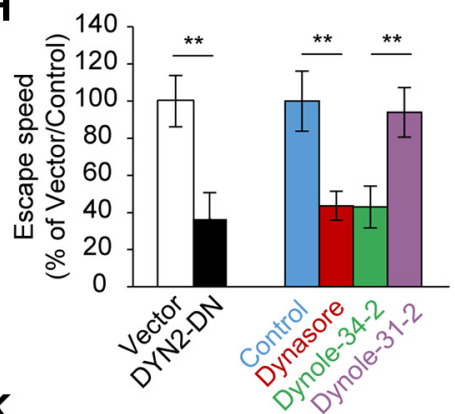

K

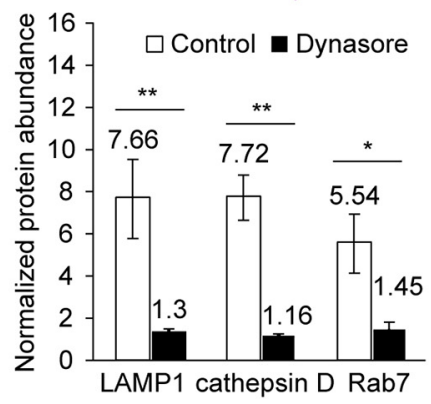

M

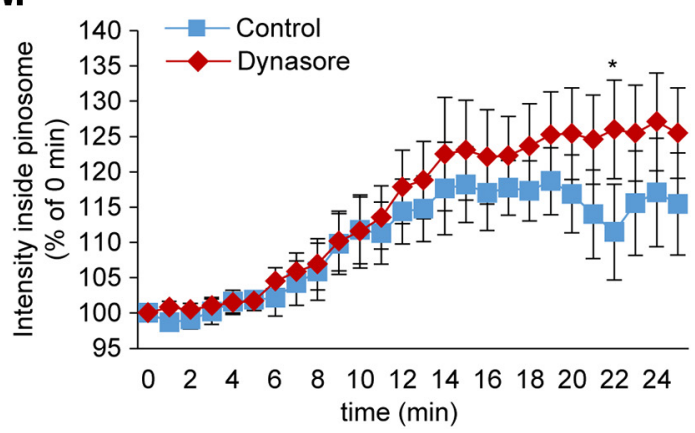

Figure 5. Function of dynamin II in the size-based sorting. $A$, Immunostaining of dynamin II (red) in cells pulse-labeled with fFD70S (lysine-fixable fluorescein-dextran, $70 \mathrm{kDa}$; green), and chased for the indicated period. Deconvolved data are displayed in $x-y$ (top), $x-z$ (bottom), and $y-z$ (right) projections. Scale bars, $5 \mu \mathrm{m}$. B, Summary data showing that the colocalization rate of fFD70S and dynamin II sequentially increased from 0 to $20 \mathrm{~min}$. C, D, Time-sequence images of typical pinosomes in microglia transfected with dominant-negative (Figure legend continues.) 
min, they took on more LAMP1 and by 15 min, the majority contained LAMP1, accompanied by a simultaneous loss of EEA1 (Fig. $3 A$ ). As the size-based sorting occurred primarily at $\sim 10$ min after their formation (Figs. 1,2), the sorting pinosomes thus showed primarily properties of late endosomes. Because endosomes frequently interact with lysosomes (Luzio et al., 2000), we tested whether small contents within pinosomal lumen are selectively delivered to lysosomes. Microglial cells were preloaded with LysoTracker, a commonly used acidification-sensitive marker to label lysosomes (Chazotte, 2011), followed by pulselabeling the pinosomes with A488D3S (AlexaFluor488-dextran, 3 $\mathrm{kDa})$. Live imaging of individual pinosomes at $15 \mathrm{~s}$ intervals showed that the escaped A488D3S molecules were directly targeted to lysosomes preloaded with LysoTracker (Fig. 3B). Similar results were obtained when microglial lysosomes were labeled with FM4-64, a stable and pH-insensitive dye that selectively labels lysosomes in astrocytes and microglia after prolonged incubation (Zhang et al., 2007; Li et al., 2009; Dou et al., 2012). The reliability of FM4-64 in labeling lysosomes was confirmed in LAMP1-GFP-transfected cells (Fig. 3C). Pinosomes loaded with FD70S and RD3S (tetramethylrhodamine-dextran, $3 \mathrm{kDa}$ ) were initially surrounded by lysosomes before the selective transfer of RD3S from pinosomes to nearby lysosomes (Fig. 3D,E). These results indicated that in the size-based sorting, the small contents in pinosomal lumen are selectively delivered to lysosomes.

To further verify the identity of endosomes involved in the size-based sorting, we used a magnetic bead-based isolation assay. Microglia were loaded for $5 \mathrm{~min}$ with water-soluble magnetic nanobeads of 5 or $20 \mathrm{~nm}$ in diameter and chased at specific timepoints, followed by cell disruption. The MEs were isolated by magnetic absorption, whereas CEs were collected by centrifugation (Fig. $3 F$ ). Analysis of vesicles in MEs using TEM with negative staining showed that immediately after loading, MEs isolated with either $5 \mathrm{~nm}$ (ME-5) or $20 \mathrm{~nm}$ (ME-20) beads contained vesicles with comparable size distributions, within a range of 200-1000 nm (Fig. 3G, top), confirming nonselective engulfment by pinocytosis. However, after a 15 min chase, the average size of the vesicles in ME- 5 became much smaller $(50-200 \mathrm{~nm})$ than those in ME-20 (150-350 nm; Fig. 3G, bottom), indicating a physical separation of the beads with different sizes and verifying the size-based sorting of pinosomal contents. Because the sizes of the 5 and $20 \mathrm{~nm}$ beads resemble the sizes of dextrans of 3 $\mathrm{kDa}(\sim 2.36 \mathrm{~nm}$ in diameter $)$ and $70 \mathrm{kDa}(\sim 15.01 \mathrm{~nm}$ in diame-

$\leftarrow$

(Figure legend continued.) dynamin II plasmids (D) or empty vector (C). Cells were pulselabeled with RD70S (red) and A680D3S (green) and chased for the indicated times. Arrowheads indicate dextrans that diffused out of the pinosomes. Scale bars, $5 \mu \mathrm{m}$. $\boldsymbol{E}-\boldsymbol{G}$, Live imaging of microglial pinosomes pulse-labeled with TD3S (red) and FD70S (green). Cells were preincubated with $40 \mu \mathrm{m}$ dynasore $(\boldsymbol{F}, \boldsymbol{G})$ or DMSO (control, $\boldsymbol{E}$ ). Arrowheads indicate dextrans that diffused out of pinosomes. Scale bars, $5 \mu \mathrm{m}$. $\boldsymbol{H}$, Quantitative data showing that the sorting speed ratio during a 15 min chase was impaired with dominant-negative dynamin II (DYN2-DN) transfection or in cells treated with, dynasore or Dynole-34-2, but not Dynole-31-2 (negative control for Dynole-34-2). I, Quantitative data showing that dynasore treatment did not affect microglial pinocytosis. J, Western blots of the protein abundance in MEs or CEs isolated from dynasore-treated microglia by the magnetic-bead-based isolation assay. $\boldsymbol{K}$, Quantitative data of $J$ combined with the DMSO control group. The protein abundance of each lysosomeassociated protein in MEs was normalized to that in CEs. Data are then normalized to the data from the ME-20 group (data from 5 independent experiments). $\boldsymbol{L}, \boldsymbol{M}$, Quantitative data summarizing the time course changes of fluorescent intensity of LysoTracker outside $(\boldsymbol{L})$ or inside the FD70S-labeled pinosomes $(\boldsymbol{M})$. Microglial cells were prelabeled with LysoTracker and subsequently pulse-labeled with FD70S (data from 4 independent experiments). Data show mean \pm SEM from three independent experiments unless otherwise specified $\left({ }^{* * *} p<0.001\right.$; ${ }^{* *} p<$ $0.01 ;{ }^{*} p<0.05 ;$ ANOVA with Tukey's test). ter) respectively (Haller, 1977), similar mechanisms are likely to be involved in the size-dependent separation of the beads and the size-based sorting of dextrans. If smaller molecules were selectively delivered to lysosomes as demonstrated above, the ME-5 fraction would contain more lysosome-related proteins than the ME-20 fraction after a 15 min chase. Indeed, Western blot analysis of the endosomal fractions revealed that ME-5 lysates contained substantially more $(>5$-fold) lysosomal proteins such as LAMP1, cathepsin D, and Rab7, but less of the early endosome marker, Rab5, than the ME-20 lysates did (Fig. $3 \mathrm{H}, \mathrm{I}$ ). We also determined the time dependence of the size-based sorting with the magnetic bead-based assay. The protein abundance of LAMP1 and cathepsin D in ME-5 markedly increased in the period between 5 and $15 \mathrm{~min}$ (Fig. 3J), consistent with the previous observations by live imaging (Figs. 1, 2). Overall, these results demonstrated that pinocytic magnetic nanobeads undergo size-based sorting similar to dextrans, and further confirmed that small contents are selectively delivered from pinosomes into lysosomes.

\section{Requirement of both fusion and fission events for size-based sorting}

Lysosomes and matured endosomes have constant interactions (Luzio et al., 2000), we thus further tested whether fusion and fission events between pinosomes and lysosomes contributed to the size-selective delivery of pinosomal contents to lysosomes. We found that GFP-tagged Rab7, a protein required for late endosomelysosome fusion (Bucci et al., 2000), was recruited to the newly formed pinosomes within $5 \mathrm{~min}$ and retained for at least $40 \mathrm{~min}$ (Fig. $4 A-C$ ), suggesting a possible involvement of Rab7 in size-based sorting. Furthermore, overexpression of constitutively active Rab7 facilitated the sorting, whereas expression of the dominant-negative Rab7 robustly decreased the sorting rate (Fig. $4 D-F$ ). These results indicated that Rab7-dependent fusion between pinosomes and lysosomes is required for size-based sorting.

We then tested whether the size-based sorting also requires the fission process. Dynamin is a GTPase functioning as a scissorlike protein for membrane fission (Roux et al., 2006). Three subtypes of dynamin have been found in mammals, among which dynamin I and III are mainly expressed in neurons and neuroendocrine cells in the brain, whereas dynamin II is ubiquitously expressed (Henley et al., 1999; Ferguson and De Camilli, 2012). We observed the recruitment of dynamin II to the newly formed pinosomes in $10 \mathrm{~min}$, the time point when size-based sorting began (Fig. $5 A, B$ ). To determine whether dynamin II dysfunction affects the size-based sorting, microglial cells were transfected with empty vector or the dominant-negative form of dynamin II (dynamin 2-DN). Live imaging showed that the selective outward delivery of $3 \mathrm{kDa}$ dextran from pinosomes was inhibited in cells transfected with dynamin 2-DN, but not in those transfected with empty vector (Fig. 5C, D, H). Inhibition of dynamin II activity with the dynamin inhibitor, dynasore (Macia et al., 2006) or Dynole-34-2 (Hill et al., 2009) but not Dynole31-2 (negative control for Dynole-34-2), also markedly blocked the size-based sorting (Fig. $5 E-H$ ), as demonstrated by the retention of the smaller dextran $(3 \mathrm{kDa})$ within the pinosomes (in most cases, $\sim 70 \%$; Fig. $5 F$ ), and nonselective delivery of both the 70 and $3 \mathrm{kDa}$ dextrans ( $~ 30 \%$; Fig. $5 G)$, which may be explained by an incomplete blockade of membrane fission and expansion of the fusion pore caused by dynasore-induced partial inhibition of dynamin function. In either case, the size-based sorting of pinosomal contents was impaired as a result of dynamin inhibition, we thus did not specifically distinguish these conditions in the following investigations. We also confirmed that dynasore- 
A

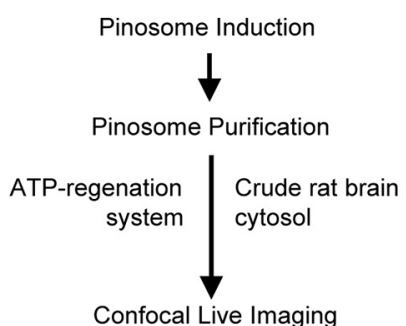

D

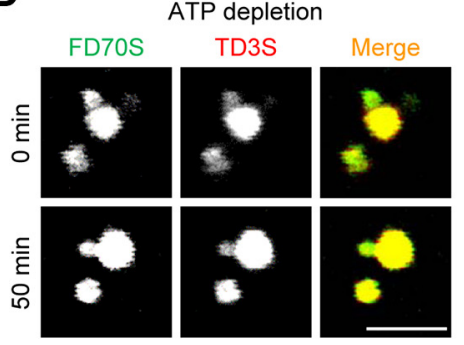

G

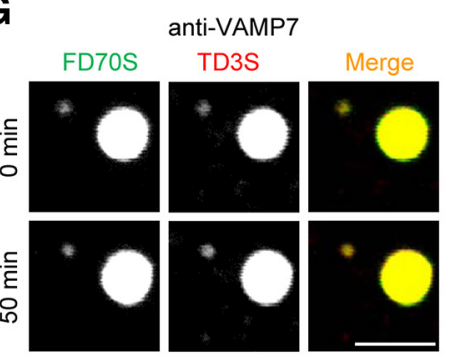

J

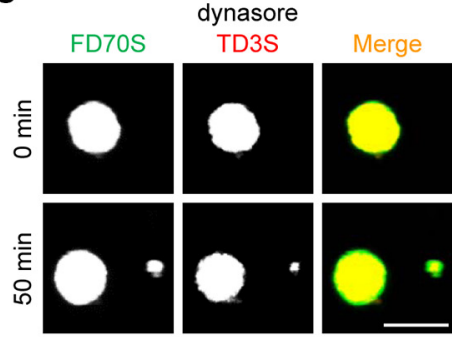

B

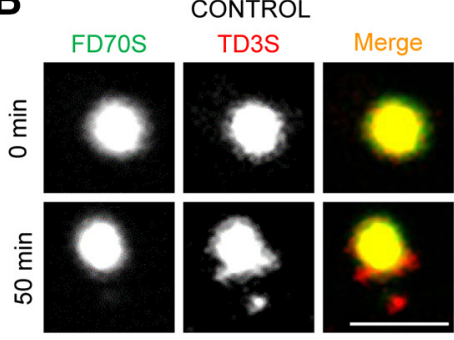

E

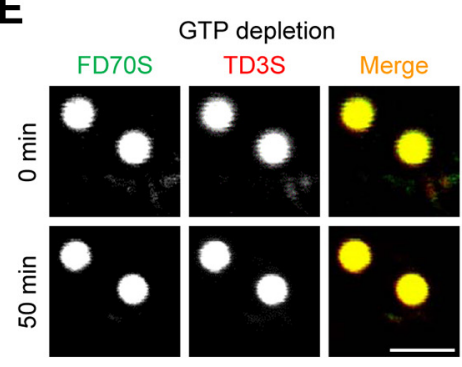

H

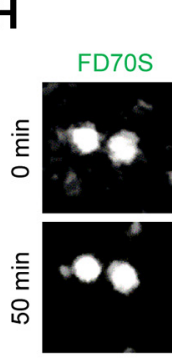

anti-STX8

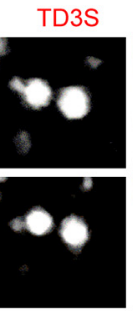

K

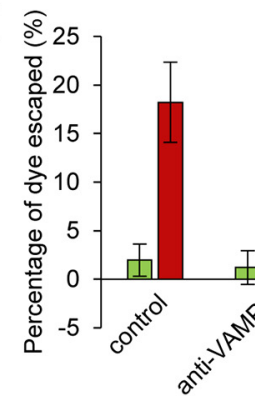

C
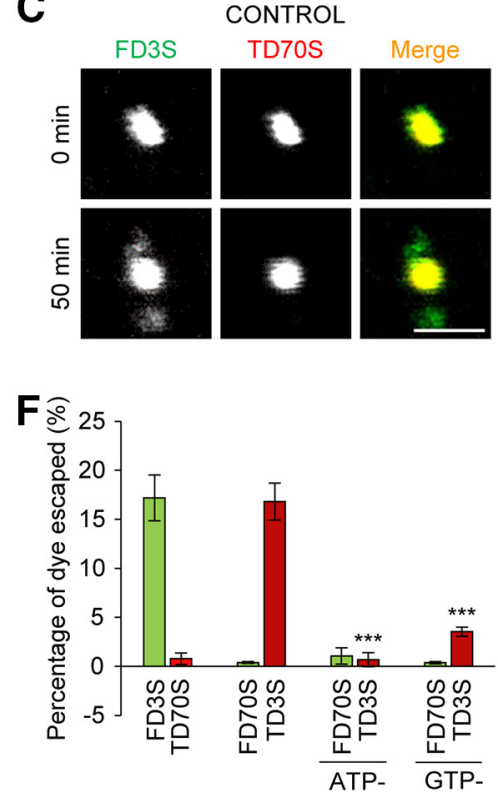

I

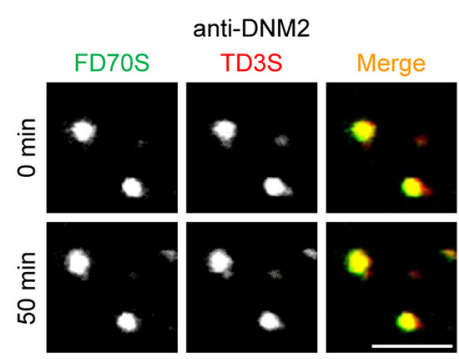

Figure 6. Size-based sorting in vitro. $\boldsymbol{A}$, Flowchart of the cell-free in vitro system. $\boldsymbol{B}, \boldsymbol{C}$, Time-sequence images of pinosomes labeled with FD70S and TD3S ( $\boldsymbol{B}$ ) or FD3S and TD70S ( $\boldsymbol{C}$ ) in the cell-free system. Scale bars, $5 \mu \mathrm{m}$. $\boldsymbol{D}, \boldsymbol{E}$, Time-sequence images of pinosomes labeled with FD70S and TD3S in the cell-free system depleted of ATP ( $\boldsymbol{D})$ or GTP $(\boldsymbol{E})$. Scale bars, $5 \mu \mathrm{m}$. $\boldsymbol{F}$, Quantitative data of $\boldsymbol{B}-\boldsymbol{E}$ summarizing the percentage of indicated dye that diffused out of pinosomes in each case ( ${ }^{* * *} p<0.001$ compared with diffusion rate of TD3S in the FD70S-TD3S control group). $\mathbf{G}-\boldsymbol{I}$, Time-sequence images of pinosomes pulse-labeled with FD70S and TD3S in the cell-free system with immunodepletion of VAMP7 (G), syntaxin 8 (STX8, $\boldsymbol{H})$ or dynamin II (DNM2, I). Scale bars, $5 \boldsymbol{\mu m}$. $\boldsymbol{J}$, Time-sequence images of pinosomes labeled with FD70S and TD3S in the cell-free system containing $40 \mu$ m dynasore. Scale bar, $5 \mu \mathrm{m}$. $\boldsymbol{K}, \mathbf{Q u a n t i t a t i v e ~ d a t a ~ s u m m a r i z i n g ~ t h e ~ e f f e c t ~ o f ~ d y n a s o r e ~}$ treatment or immunodepletion of VAMP7, STX8, DNM2, SNAP23, or SNAP25 on the size-based sorting $\left({ }^{* * *} p<0.001 ;{ }^{* *} p<0.01\right.$, compared with the diffusion rate of TD3S in the control group; ANOVA with Tukey's test). Data show mean \pm SEM from five independent experiments.

treatment did not impair microglial pinocytosis (Fig. 5I). To avoid side effects of long-term dynamin-inhibition and due to low transfection efficiency of immune cells, we inhibited the dynamin activity with short-term dynasore-treatment in further experiments. We tested the effect of dynamin-inhibition in the magnetic bead-based isolation assay. In contrast to the preferential inclusion of lysosomal proteins in ME-5 in the control (Figs. $3 \mathrm{H}, \mathrm{I}, 5 \mathrm{~K})$, dynasore treatment resulted in the equal inclusion of lysosomal proteins in both ME-5 and ME-20 in the magnetic bead-based assay (Fig. $5 \mathrm{~J}, \mathrm{~K}$ ), confirming the loss of size-selective delivery upon dynamin inhibition. We noticed that Rab7interference and dynamin II-inhibition resulted in comparable reduction in size-based sorting, but appeared to have differential effect on the pinosomal morphology: Expression of dominantnegative Rab7 resulted in static pinosomes with no shape change, whereas dynasore-treated pinosomes were as dynamic as those in untreated cells, suggesting that dynasore-treatment did not affect the pinosome-lysosome fusion. To further test this idea, we analyzed the effect of dynasore on pinosome-lysosome fusion. In microglial cells incubated with LysoTracker, dynasore-treatment resulted in a reduction in LysoTracker intensity around pinosomes, and slightly increased intensity inside pinosomes (Fig. $5 L, M)$, suggesting unimpaired fusion between pinosomes and lysosomes. Together, these results demonstrated that both fusion 
A

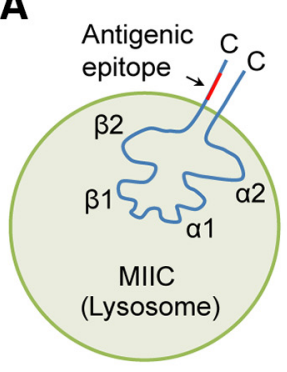

\section{E}

\section{OT-II C57/B6}

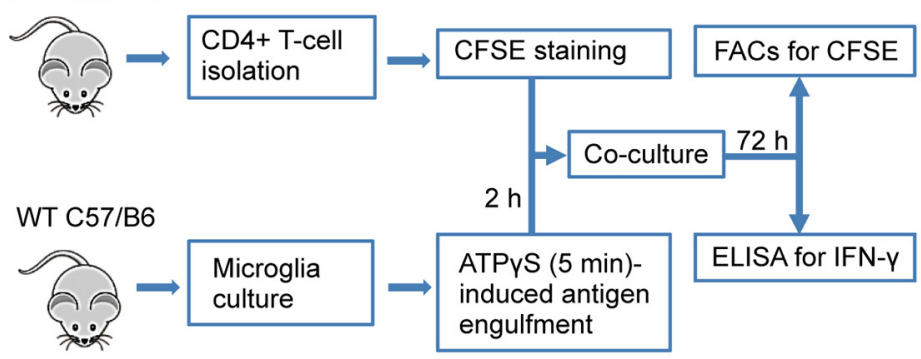

G
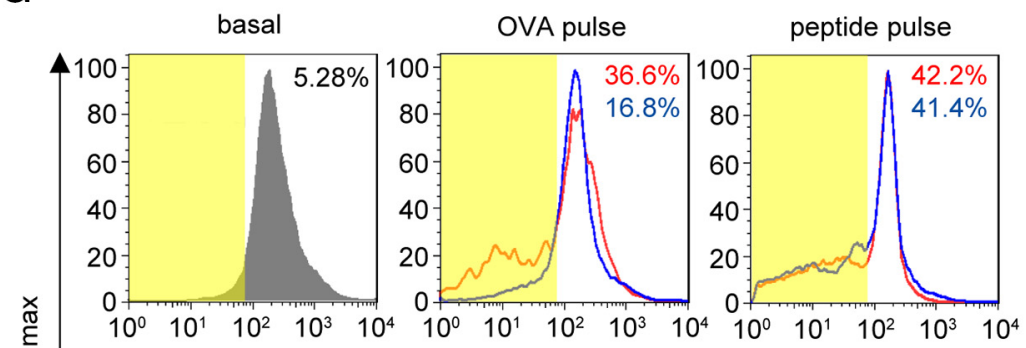

Normalized MHC II abundance

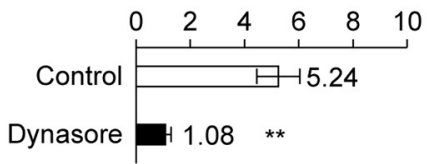

B Control

Dynasore

Dynasor
C

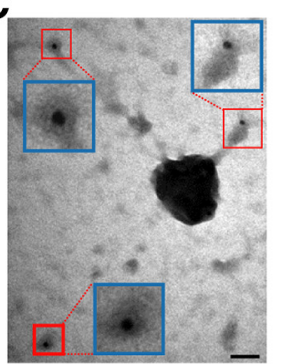

D

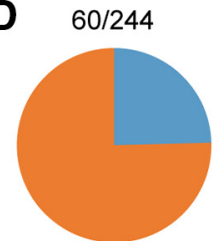

$5 \mathrm{~nm} \mathrm{ME}$

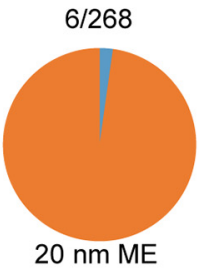

MHC II positive endosomes

$\mathrm{MHC}$ II negative endosomes
$\mathbf{F}$

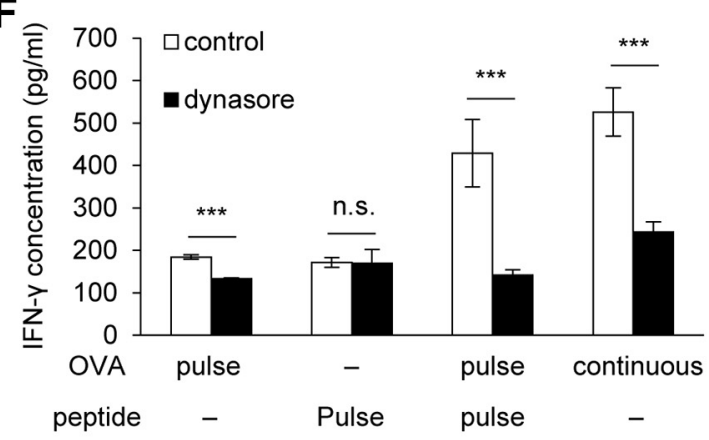

H — basal — DMSO _ dynasore
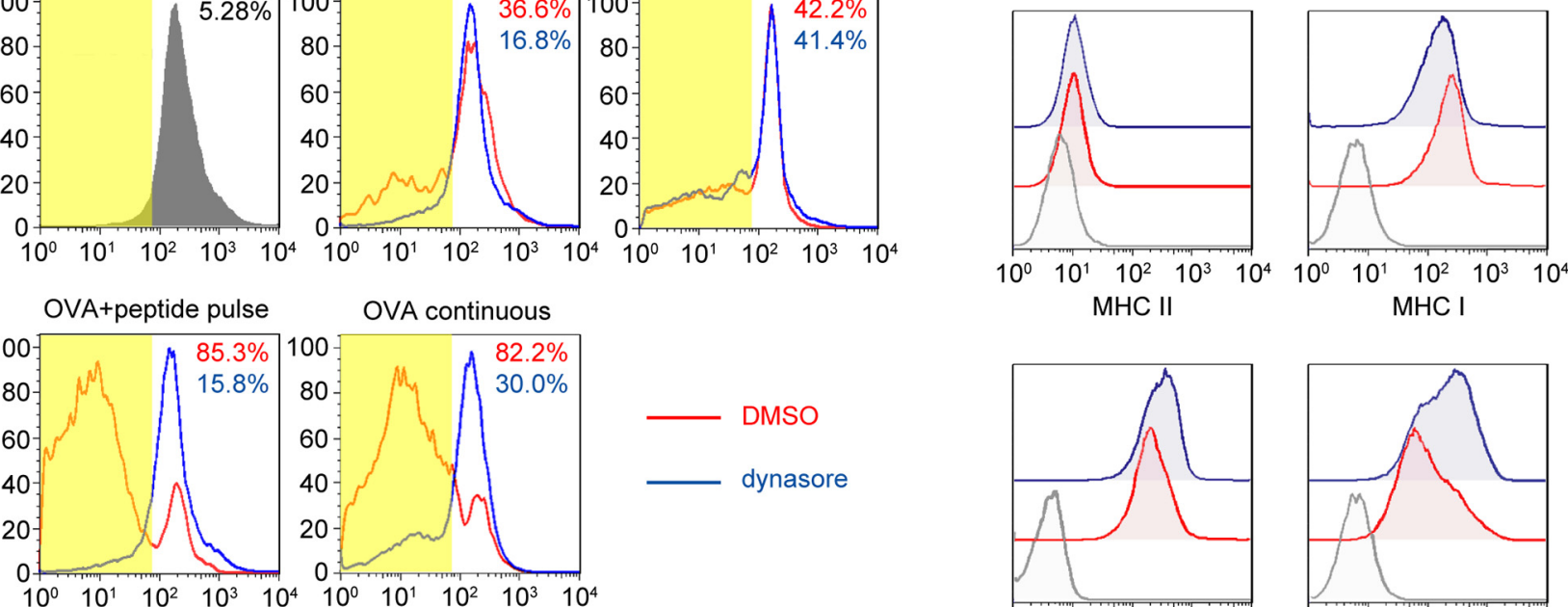

- DMSO
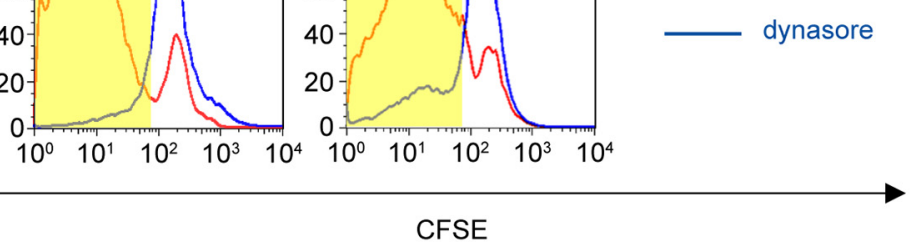

J

I
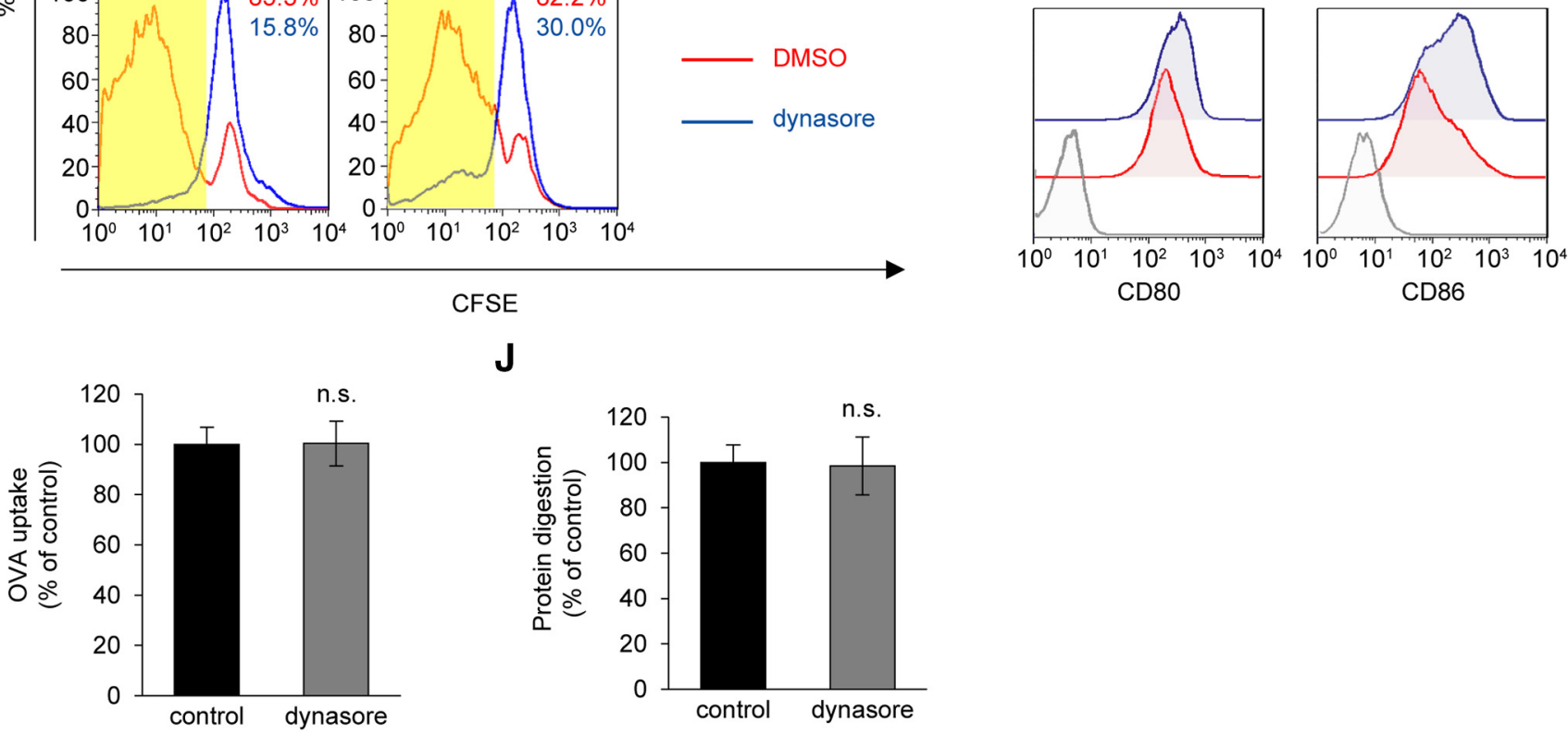

Figure 7. Function of the size-based sorting in antigen presentation. A, Diagram showing that the anti-MHC II pAb used in the following experiments specifically recognized the cytoplasmic terminal of the MHC II protein. B, Sample images (top) and quantitative data (bottom) of Western blot analysis showing the protein abundance of MHC II in MEs or CEs isolated from cells treated with DMSO (control) or $40 \mu \mathrm{m}$ dynasore. Data are normalized to (Es and then normalized to the result from the ME-20 group (data from 5 independent experiments). C, TEM image of MHC III immunogold labeling combined with negative staining of ME-5 isolated after a $5 \mathrm{~min}$ pulse and $15 \mathrm{~min}$ chase. Blue boxes show the magnified area in the corresponding red boxes. $\boldsymbol{D}$, Quantitative data showing the number of MHC II-positive endosomes in all counted endosomes in the ME- 5 or ME- 20 groups. $E$, Flowchart of the antigen presentation assay. $F$, ELISA assessment of the IFN- $\gamma$ concentration in the antigen presentation assay. Cells were loaded with indicated antigens and treated with DMSO (control) or $40 \mu \mathrm{M}$ dynasore. G, Flow cytometry of T-cell (Figure legend continues.) 
and fission are essential for the size-based sorting of pinosomal luminal contents.

\section{Reconstruction of size-based sorting in a cell-free system}

To further confirm that the size-based sorting of pinosomal luminal contents requires both fission and fusion between pinosomes and lysosomes, we reconstructed size-based sorting in vitro using a cell-free system. The pinosomes were loaded with fluorescent dextrans together with $20 \mathrm{~nm}$ magnetic nanoparticles and isolated by the magnet-based assay. Isolated pinosomes were incubated in the ATP-regeneration system and crude rat brain cytosol (Fig. 6A). In this assay, we also found that small dextrans (TD3S or FD3S) escaped from the pinosomes and larger dextrans (FD70S or TD70S) were retained (Fig. 6B,C,F), consistent with the results from live cells. Moreover, the in vitro sorting was completely blocked by the depletion of ATP and seriously impaired by the removal of GTP (Fig. $6 D-F$ ), indicating the requirement of both ATP and GTP in size-based sorting. We then took advantage of the in vitro system to further investigate the sorting mechanism.

Both VAMP7 and syntaxin8 are SNARE proteins mediating fusion between late endosomes and lysosomes (Pryor et al., 2004). Immunodepletion of either VAMP7 (Fig. 6G,K) or syntaxin 8 (STX8, Fig. $6 H, K$ ) inhibited the size-based sorting in the in vitro system, whereas immunodepletion of SNAP25 or SNAP23, which mediate fusion between late endosomes and the plasma membrane (Zhang et al., 2002), had no effect on the size-based sorting (Fig. $6 \mathrm{~K}$ ). These results further confirmed the requirement of pinosome-lysosome fusion in the sorting process. Moreover, blocking dynamin function by addition of anti-dynamin II antibody or $40 \mu \mathrm{M}$ dynasore also inhibited the size-based sorting (Fig. 6I-K), supporting the hypothesis that the fission process is required for this mechanism. Altogether, data from the reconstituted cell-free system further verified that the size-based sorting of pinosomal luminal contents requires both fission and fusion between pinosomes and lysosomes.

\section{Involvement of size-based sorting in antigen processing}

In antigen-presenting cells, engulfed exogenous proteins of varying sizes (tens to hundreds of $\mathrm{kDa}$ ) must be hydrolyzed into short antigenic peptides (12-25 aa, 1-3 kDa) before being loaded onto MHC class II molecules in MHC class II containing compartments (MIICs), organelles with lysosome-like properties (Kleijmeer et al., 1997; Watts, 2004; Blum et al., 2013). We have shown that internalized proteins undergo hydrolysis inside the pinosomes (Fig. 1), followed by selective delivery of small molecules (including the derived peptides) to lysosomes (Fig. 3). Importantly, the size-based sorting distinguished between 70 and $3 \mathrm{kDa}$ molecules, which are reminiscent of the sizes of natural proteins and antigenic peptides respectively. We thus hypothesized that the size-based sorting of pinosomal luminal contents is

$\leftarrow$

(Figure legend continued.) proliferation in the antigen presentation assay. T cells were cocultured for $3 \mathrm{~d}$ with microglia loaded with indicated antigens and treated with DMSO (control, red) or $40 \mu \mathrm{m}$ dynasore (blue). The group without any antigen loading and treatment were taken as basal. The horizontal axis shows CFSE intensity. Quantitative results are expressed in terms of the percentage of peak area in yellow zone, representing the T-cell proliferation; larger percentage means more T-cell proliferation. $\boldsymbol{H}$, Flow cytometry of the microglia surface expression of $\mathrm{MHC}$ II, MHC I, CD80, and CD86. Cells were treated with OVA together with $40 \mu \mathrm{M}$ dynasore (blue) or with DMSO (red) for $72 \mathrm{~h}$. Cells without any treatment were taken as basal (gray). The horizontal axis shows intensity of indicated molecule. I, J, OVA uptake by microglia $(I)$, or DQ-OVA digestion by microglia $(J)$. Data show mean \pm SEM from three independent experiments unless otherwise specified ${ }^{* * *} p<0.001$; ANOVA with Tukey's test). involved in antigen processing by the selective delivery of smaller antigenic peptides rather than larger proteins into the MIICs.

To test this idea, an antibody that recognizes the $\mathrm{C}$-terminal cytoplasmic domain of MHC II (Fig. 7A) was used to determine the abundance of MHC II in the ME fractions isolated by the magnetic bead-based assay. We found that MHC II proteins were preferentially included in ME- 5 rather than in ME-20 lysates and that dynasore treatment removed the differences in MHC II abundance between ME-5 and ME-20 (Fig. 7B). TEM immunogold labeling of MHC II combined with negative staining of ME samples also revealed that ME-5 contained more MHC IIpositive endosomes than ME-20 (Fig. 7C,D). These results indicated that during the size-based sorting, the small pinosomal luminal contents are selectively delivered to MIICs, supporting the idea that this mechanism participates in antigen processing.

We further assessed whether disruption of the size-based sorting by dynasore treatment affects the antigen-presentation efficiency. The experimental procedure is shown in Figure $7 E$ and details are in Materials and Methods. Briefly, full-length OVA protein or OVA323-339 peptide, which represent antigenic proteins and peptides respectively, was internalized by ATP $\gamma S$ triggered pinocytosis for $5 \mathrm{~min}$. Then, microglial cells were treated with dynasore or DMSO for $2 \mathrm{~h}$ followed by coculture in drug-free medium with CD4+ T cells isolated from OT-II mice, which predominantly consisted of $\mathrm{CD} 4+\mathrm{T}$ cells that specifically recognize OVA323-339 (Robertson et al., 2000). The efficiency of antigen presentation was evaluated based on the proliferative rate of CD4 + T cells and the amount of interferon-gamma (IFN- $\gamma$ ) secreted. Strikingly, we found that dynasore treatment dramatically decreased the efficiency of microglia in presenting the full OVA protein but not the OVA peptide, as shown by decreases in IFN- $\gamma$ secretion (Fig. $7 F$ ) and T-cell proliferation (Fig. 7G). These results indicated that dynasore treatment impairs the processing of protein antigen, but does not affect the antigen-presenting ability. Interestingly, although adding OVA proteins to the OVA peptides enhanced the antigen-presentation efficiency in control cells, it attenuated the efficiency in dynasore-treated cells (Fig. $7 F, G$ ). This effect may be attributed to the competitive inhibition of antigen-MHC II interactions by unqualified proteins or peptides that were nonselectively delivered to lysosomes in dynasore-treated cells. Further experiments showed that other processes involved in microglial antigen presentation were not significantly affected by dynasore treatment, including microglial activation (as exemplified by the surface expression of the immune activation markers MHC I, MHC II, CD80, and CD86; Fig. $7 \mathrm{H}$ ), antigen engulfment (evaluated as OVA uptake; Fig. $7 I$ ), and microglial digestion (evaluated as DQ-OVA proteolysis; Fig. $7 J)$. Altogether, these results suggested that the selective delivery of qualified antigenic peptides to the MIICs is essential for antigen presentation, consistent with a role for the size-based sorting of pinosomal luminal contents in the presentation of exogenous antigens.

\section{Discussion}

In this study, we first discovered that pinocytosed proteins are soon hydrolyzed into small peptides within the pinosomal lumen, followed by selective escape of the resulting peptides to lysosomes. We then demonstrated that the selective delivery of peptides requires both fission and fusion between pinosomes and lysosomes, resulting in selective transfer of small molecules and retention of large ones. We further provided direct evidence that this size-based sorting of luminal contents contributes to efficient antigen processing.

Conventional models of antigen presentation suggest that pinocytosed antigens are nonselectively delivered to lysosomes and 


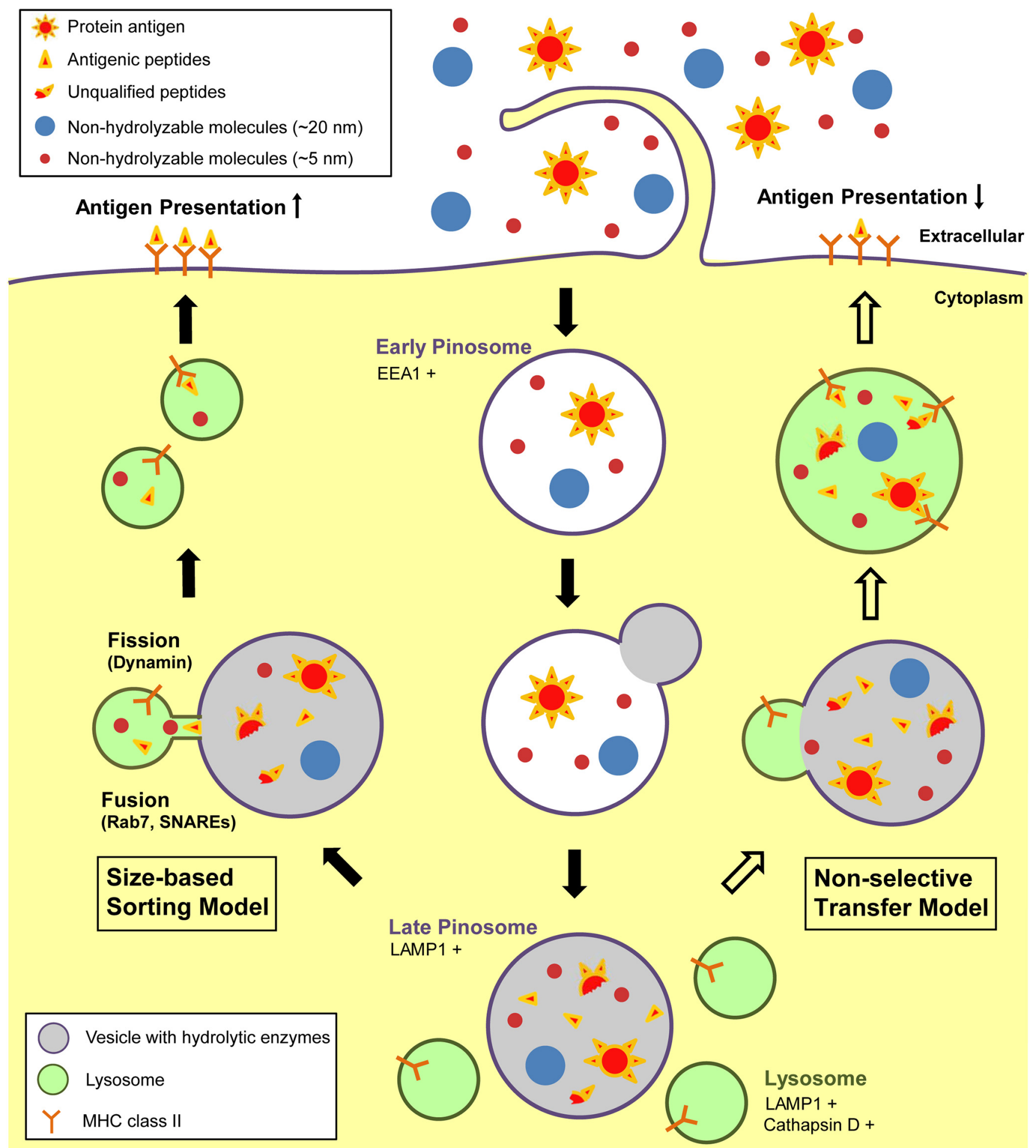

Figure 8. Hypothetical model of size-based sorting and antigen processing. After nonselective engulfment of pinocytosis, some vesicles fuse with newly formed pinosomes, which provide proteases and result in proteolysis in pinosomes. Subsequently, the pinosomal luminal contents are nonselectively transferred or size-based sorted into lysosomes. In the nonselective transfer model, all the contents are delivered into lysosomes, which cause competitive inhibition of MHC-peptide combination and less presented antigen. In the size-based sorting model, only qualified peptide $(<30 \mathrm{aa})$, as well as other small molecules are selectively delivered into lysosomes, which facilitates MHC-peptide combination and results in efficient antigen presentation.

MIICs, and both proteolysis of antigens and coupling of the resulting antigenic peptides with MHC class II molecules takes place in the same compartment (Rocha and Neefjes, 2008; Blum et al., 2013). However, this model raises the question regarding how the cell efficiently handles the repertoire of solutes within the large pinosomes and how smaller qualified peptides, amid a large amount of unqualified proteins within the MIICs, are efficiently transferred to and coupled with MHC II molecules. Based on our findings, we propose a new model for the endocytic processing of internalized antigens (Fig. 8). Antigens are first taken up by nonselective pinocytosis and hydrolyzed into small peptides within pinosomes. Next, the size-based sorting mechanism allows the 
selective transfer of only small molecules, including the antigenic peptides, into the MHC class II-containing lysosomes, a process critical for limiting the entry of nonhydrolyzed proteins or unqualified peptides. Finally, the antigenic peptides combine with MHC class II molecules, followed by the transport of MHC IIpeptide complex to the plasma membrane and presentation to $\mathrm{T}$ cells. In this model, by selectively transferring the qualified antigenic peptides to the MIICs, the competitive inhibition by nonhydrolyzed proteins or unqualified peptides is substantially prevented, thereby enhancing the antigen presentation efficiency. Our findings thus offer new insights into the selection and amplification mechanisms of antigen presentation involved in both normal immune responses and immune disorders.

Differential distribution of soluble cargoes following endocytosis has been described in macrophages (Berthiaume et al., 1995), although the underlying mechanism and physiological relevance are not clear. Vesicle budding and transient fusion are two possible mechanisms to form narrow tunnels to mediate the sizedependent mobility restriction. Vesicle budding from endosomes receives wide attention, and is responsible for selective transport of internalized receptors (Maxfield and McGraw, 2004). However, our results suggested that the size-based sorting of luminal contents in microglia is more likely mediated by transient fusion between pinosomes and lysosomes. First, the majority of small dextrans being transferred out of pinosomes were immediately delivered to lysosomes (Fig. $3 B, D, E$ ). Second, interfering with Rab7, a fusion-mediating Rab protein, or dynamin, a fission regulator, impaired the size-based selection (Figs. 4, 5). Third, results from the cell-free in vitro system also showed that the SNARE proteins VAMP7 and STX8, which mediate late endosome-lysosome fusion, were required for the size-based sorting (Fig, 6G, H,K). Together, our results tended to support the transient fusion mechanism, although the involvement of vesicle budding or other mechanisms cannot be excluded. It has recently been reported that dynasore inhibit endocytosis in dynamin-I, -II, -III, triple knock-out cells (Park et al., 2013), suggesting that proteins other than dynamin may be also targeted by dynasore. However, we provided further evidence that supports the involvement of dynamin II in the size-based sorting, including immunodepletion (Fig. 6I,K), and application of dominant-negative dynamin II (Fig. $5 D, H$ ) and another dynamin inhibitor, dynole-34-2 (Fig. $5 H$ ). Nevertheless, more investigations are required to identify molecules functioning in the fusion and fission events during size-based sorting.

We found that the pinosomal lumen became acidified within 5 min (Fig. $1 K, L$ ), suggesting that proton pumps are rapidly transported to pinosomes to provide an appropriate environment for protein degradation. Although we have not identified the vesicles responsible for providing proton pumps and hydrolytic proteases to pinosomes, early endosomes, which contain a high density of proton pumps and a variety of proteases and fuse with pinosomes at an early stage (Runquist and Havel, 1991; Phillips and Thomas, 2006; Guha and Padh, 2008), are potential candidates. Consistent with this idea, we found that early endosomes associated with pinosomes immediately after pinosome formation (Fig. 3A). It is also possible that there are different subsets of lysosomes, with some providing proton pumps and enzymes by fullcollapse fusion, whereas others take qualified peptides away by transient fusion. Alternatively, newly synthesized proton pumps and enzymes may be directly delivered to pinosomes via transport vesicles (Gu et al., 2001; Huotari and Helenius, 2011).

Microglia are the main immune cells in CNS, constantly detecting the environment and engulfing apoptotic cells, cellular debris, DNA fragments, and abnormal proteins (Aloisi, 2001; Saijo and Glass, 2011). However, the intracellular trafficking of engulfed soluble substances remains largely unknown, in despite of the fact that the endocytic trafficking of endosomal luminal contents is an essential process for nutrient allocation, bacterial and viral invasion, drug delivery, and antigen processing (Slevogt et al., 2007; Mercer and Helenius, 2009; Reyes-Reyes et al., 2010; Blum et al., 2013; Commisso et al., 2013). Our study reveals a size-dependent pinosome-lysosome trafficking pathway that contributes to efficient antigen processing and presentation in microglia, providing new insights into the mechanisms of neuroimmune responses and neuroinflammation. In EAE model of multiple sclerosis, microglia are responsible for inducing immune cell infiltration, initiating immune responses, and producing inflammatory cytokines (Li et al., 2003; Olson and Miller, 2004; Chastain et al., 2011). Deficient microglial functions result in reduced disease onset, progression, and demyelination (Heppner et al., 2005; Ponomarev et al., 2006). It would be of great interest to investigate whether the size-based sorting in microglia is a key process during disease development in the EAE model of multiple sclerosis, and whether the disease process is affected by manipulating the size-based sorting in microglia. In addition, other than the role as immune cells, recent studies reveal important roles of microglia in regulating synaptic pruning, synaptic transmission, and neuronal growth (Li et al., 2012; Schafer et al., 2012; Ueno et al., 2013). It would be worthwhile to further investigate whether endocytic trafficking of luminal contents in microglia, particularly, the size-based sorting mechanism, is involved in the above mentioned processes that fulfill the role of microglia in immunosurveillance and maintenance of homeostasis in CNS.

\section{References}

Aloisi F (2001) Immune function of microglia. Glia 36:165-179. CrossRef Medline

Barysch SV, Jahn R, Rizzoli SO (2010) A fluorescence-based in vitro assay for investigating early endosome dynamics. Nat Protoc 5:1127-1137. CrossRef Medline

Berthiaume EP, Medina C, Swanson JA (1995) Molecular size-fractionation during endocytosis in macrophages. J Cell Biol 129:989-998. CrossRef Medline

Blum JS, Wearsch PA, Cresswell P (2013) Pathways of antigen processing. Annu Rev Immunol 31:443-473. CrossRef Medline

Bonifacino JS, Rojas R (2006) Retrograde transport from endosomes to the trans-Golgi network. Nat Rev Mol Cell Biol 7:568-579. CrossRef Medline

Bucci C, Thomsen P, Nicoziani P, McCarthy J, van Deurs B (2000) Rab7: a key to lysosome biogenesis. Mol Biol Cell 11:467-480. CrossRef Medline

Chastain EM, Duncan DS, Rodgers JM, Miller SD (2011) The role of antigen presenting cells in multiple sclerosis. Biochim Biophys Acta 1812:265274. CrossRef Medline

Chazotte B (2009) Labeling pinocytotic vesicles and cytoplasm with fluorescent dextrans or ficolls for imaging. Cold Spring Harb Protoc 2009:pdb.prot4951. CrossRef Medline

Chazotte B (2011) Labeling lysosomes in live cells with LysoTracker. Cold Spring Harb Protoc 2011:pdb.prot5571. CrossRef Medline

Commisso C, Davidson SM, Soydaner-Azeloglu RG, Parker SJ, Kamphorst JJ, Hackett S, Grabocka E, Nofal M, Drebin JA, Thompson CB, Rabinowitz JD, Metallo CM, Vander Heiden MG, Bar-Sagi D (2013) Macropinocytosis of protein is an amino acid supply route in Ras-transformed cells. Nature 497:633-637. CrossRef Medline

Davis CG, Goldstein JL, Südhof TC, Anderson RG, Russell DW, Brown MS (1987) Acid-dependent ligand dissociation and recycling of LDL receptor mediated by growth factor homology region. Nature 326:760-765. CrossRef Medline

Dou Y, Wu HJ, Li HQ, Qin S, Wang YE, Li J, Lou HF, Chen Z, Li XM, Luo QM, Duan S (2012) Microglial migration mediated by ATP-induced ATP release from lysosomes. Cell Res 22:1022-1033. CrossRef Medline

Ferguson SM, De Camilli P (2012) Dynamin, a membrane-remodelling GTPase. Nat Rev Mol Cell Biol 13:75-88. CrossRef Medline 
Gu F, Crump CM, Thomas G (2001) Trans-Golgi network sorting. Cell Mol Life Sci 58:1067-1084. CrossRef Medline

Guha S, Padh H (2008) Cathepsins: fundamental effectors of endolysosomal proteolysis. Indian J Biochem Biophys 45:75-90. Medline

Haller W (1977) Critical permeation size of dextran molecules. Macromolecules 10:83-86. CrossRef

Harding C, Heuser J, Stahl P (1983) Receptor-mediated endocytosis of transferrin and recycling of the transferrin receptor in rat reticulocytes. J Cell Biol 97:329-339. CrossRef Medline

Henley JR, Cao H, McNiven MA (1999) Participation of dynamin in the biogenesis of cytoplasmic vesicles. FASEB J 13:S243-247. Medline

Heppner FL, Greter M, Marino D, Falsig J, Raivich G, Hövelmeyer N, Waisman A, Rülicke T, Prinz M, Priller J, Becher B, Aguzzi A (2005) Experimental autoimmune encephalomyelitis repressed by microglial paralysis. Nat Med 11:146-152. CrossRef Medline

Hill TA, Gordon CP, McGeachie AB, Venn-Brown B, Odell LR, Chau N, Quan A, Mariana A, Sakoff JA, Chircop M, Robinson PJ, McCluskey A (2009) Inhibition of dynamin mediated endocytosis by the dynoles: synthesis and functional activity of a family of indoles. J Med Chem 52:37623773. CrossRef Medline

Huotari J, Helenius A (2011) Endosome maturation. EMBO J 30:34813500. CrossRef Medline

Kerr MC, Teasdale RD (2009) Defining macropinocytosis. Traffic 10:364371. CrossRef Medline

Kerr MC, Lindsay MR, Luetterforst R, Hamilton N, Simpson F, Parton RG, Gleeson PA, Teasdale RD (2006) Visualisation of macropinosome maturation by the recruitment of sorting nexins. J Cell Sci 119:3967-3980. CrossRef Medline

Kleijmeer MJ, Morkowski S, Griffith JM, Rudensky AY, Geuze HJ (1997) Major histocompatibility complex class II compartments in human and mouse B lymphoblasts represent conventional endocytic compartments. J Cell Biol 139:639-649. CrossRef Medline

Lanzavecchia A (1996) Mechanisms of antigen uptake for presentation. Curr Opin Immunol 8:348-354. CrossRef Medline

Li D, Hérault K, Oheim M, Ropert N (2009) FM dyes enter via a storeoperated calcium channel and modify calcium signaling of cultured astrocytes. Proc Natl Acad Sci U S A 106:21960-21965. CrossRef Medline

Li HQ, Chen C, Dou Y, Wu HJ, Liu YJ, Lou HF, Zhang JM, Li XM, Wang H, Duan S (2013) P2Y4 receptor-mediated pinocytosis contributes to amyloid beta-induced self-uptake by microglia. Mol Cell Biol 33:4282-4293. CrossRef Medline

Li J, Gran B, Zhang GX, Ventura ES, Siglienti I, Rostami A, Kamoun M (2003) Differential expression and regulation of IL-23 and IL-12 subunits and receptors in adult mouse microglia. J Neurol Sci 215:95-103. CrossRef Medline

Li Y, Du XF, Liu CS, Wen ZL, Du JL (2012) Reciprocal regulation between resting microglial dynamics and neuronal activity in vivo. Dev Cell 23: 1189-1202. CrossRef Medline

Liu X, Lu L, Yang Z, Palaniyandi S, Zeng R, Gao LY, Mosser DM, Roopenian DC, Zhu X (2011) The neonatal FcR-mediated presentation of immune-complexed antigen is associated with endosomal and phagosomal $\mathrm{pH}$ and antigen stability in macrophages and dendritic cells. J Immunol 186:4674-4686. CrossRef Medline

Luzio JP, Rous BA, Bright NA, Pryor PR, Mullock BM, Piper RC (2000) Lysosome-endosome fusion and lysosome biogenesis. J Cell Sci 113: 1515-1524. Medline

Macia E, Ehrlich M, Massol R, Boucrot E, Brunner C, Kirchhausen T (2006) Dynasore, a cell-permeable inhibitor of dynamin. Dev Cell 10:839-850. CrossRef Medline

Maxfield FR, McGraw TE (2004) Endocytic recycling. Nat Rev Mol Cell Biol 5:121-132. CrossRef Medline

Mercer J, Helenius A (2009) Virus entry by macropinocytosis. Nat Cell Biol 11:510-520. CrossRef Medline

Nimmerjahn A, Kirchhoff F, Helmchen F (2005) Resting microglial cells are highly dynamic surveillants of brain parenchyma in vivo. Science 308: 1314-1318. CrossRef Medline

Olson JK, Miller SD (2004) Microglia initiate central nervous system innate and adaptive immune responses through multiple TLRs. J Immunol 173: 3916-3924. CrossRef Medline

Park RJ, Shen H, Liu L, Liu X, Ferguson SM, De Camilli P (2013) Dynamin triple knockout cells reveal off target effects of commonly used dynamin inhibitors. J Cell Sci 126:5305-5312. CrossRef Medline
Phillips MD, Thomas GH (2006) Brush border spectrin is required for early endosome recycling in Drosophila. J Cell Sci 119:1361-1370. CrossRef Medline

Ponomarev ED, Shriver LP, Dittel BN (2006) CD40 expression by microglial cells is required for their completion of a two-step activation process during central nervous system autoimmune inflammation. J Immunol 176:1402-1410. CrossRef Medline

Pryor PR, Mullock BM, Bright NA, Lindsay MR, Gray SR, Richardson SC, Stewart A, James DE, Piper RC, Luzio JP (2004) Combinatorial SNARE complexes with VAMP7 or VAMP8 define different late endocytic fusion events. EMBO Rep 5:590-595. CrossRef Medline

Racoosin EL, Swanson JA (1993) Macropinosome maturation and fusion with tubular lysosomes in macrophages. J Cell Biol 121:1011-1020. CrossRef Medline

Reyes-Reyes EM, Teng Y, Bates PJ (2010) A new paradigm for aptamer therapeutic AS1411 action: uptake by macropinocytosis and its stimulation by a nucleolin-dependent mechanism. Cancer Res 70:8617-8629. CrossRef Medline

Robertson JM, Jensen PE, Evavold BD (2000) DO11.10 and OT-II T cells recognize a C-terminal ovalbumin 323-339 epitope. J Immunol 164: 4706-4712. CrossRef Medline

Rocha N, Neefjes J (2008) MHC class II molecules on the move for successful antigen presentation. EMBO J 27:1-5. CrossRef Medline

Rong Y, Liu M, Ma L, Du W, Zhang H, Tian Y, Cao Z, Li Y, Ren H, Zhang C, Li L, Chen S, Xi J, Yu L (2012) Clathrin and phosphatidylinositol-4,5bisphosphate regulate autophagic lysosome reformation. Nat Cell Biol 14:924-934. CrossRef Medline

Roux A, Uyhazi K, Frost A, De Camilli P (2006) GTP-dependent twisting of dynamin implicates constriction and tension in membrane fission. Nature 441:528-531. CrossRef Medline

Runquist EA, Havel RJ (1991) Acid hydrolases in early and late endosome fractions from rat liver. J Biol Chem 266:22557-22563. Medline

Saijo K, Glass CK (2011) Microglial cell origin and phenotypes in health and disease. Nat Rev Immunol 11:775-787. CrossRef Medline

Sarkar K, Kruhlak MJ, Erlandsen SL, Shaw S (2005) Selective inhibition by rottlerin of macropinocytosis in monocyte-derived dendritic cells. Immunology 116:513-524. CrossRef Medline

Schafer DP, Lehrman EK, Kautzman AG, Koyama R, Mardinly AR, Yamasaki R, Ransohoff RM, Greenberg ME, Barres BA, Stevens B (2012) Microglia sculpt postnatal neural circuits in an activity and complementdependent manner. Neuron 74:691-705. CrossRef Medline

Slevogt H, Seybold J, Tiwari KN, Hocke AC, Jonatat C, Dietel S, Hippenstiel S, Singer BB, Bachmann S, Suttorp N, Opitz B (2007) Moraxella catarrhalis is internalized in respiratory epithelial cells by a trigger-like mechanism and initiates a TLR2- and partly NOD1-dependent inflammatory immune response. Cell Microbiol 9:694-707. CrossRef Medline

Sodhi A, Gupta P (1988) Study on pinocytosis and antigen presentation by murine peritoneal macrophages to $\mathrm{T}$ cells in vitro after cisplatin treatment. Arch Immunol Ther Exp (Warsz) 36:315-323. Medline

Ueno M, Fujita Y, Tanaka T, Nakamura Y, Kikuta J, Ishii M, Yamashita T (2013) Layer $\mathrm{V}$ cortical neurons require microglial support for survival during postnatal development. Nat Neurosci 16:543-551. CrossRef Medline

Wang D, Zheng M, Lei L, Ji J, Yao Y, Qiu Y, Ma L, Lou J, Ouyang C, Zhang X, He Y, Chi J, Wang L, Kuang Y, Wang J, Cao X, Lu L (2012) Tespal is involved in late thymocyte development through the regulation of TCRmediated signaling. Nat Immunol 13:560-568. CrossRef Medline

Watts C (2004) The exogenous pathway for antigen presentation on major histocompatibility complex class II and CD1 molecules. Nat Immunol 5:685-692. CrossRef Medline

Whistler JL, Enquist J, Marley A, Fong J, Gladher F, Tsuruda P, Murray SR, Von Zastrow M (2002) Modulation of postendocytic sorting of G protein-coupled receptors. Science 297:615-620. CrossRef Medline

Wu HJ, Liu YJ, Li HQ, Chen C, Dou Y, Lou HF, Ho MS, Li XM, Gao Z, Duan S (2014) Analysis of microglial migration by a micropipette assay. Nat Protoc 9:491-500. CrossRef Medline

Zhang X, Kim-Miller MJ, Fukuda M, Kowalchyk JA, Martin TF (2002) $\mathrm{Ca} 2+$-dependent synaptotagmin binding to SNAP-25 is essential for $\mathrm{Ca} 2+$-triggered exocytosis. Neuron 34:599-611. CrossRef Medline

Zhang Z, Chen G, Zhou W, Song A, Xu T, Luo Q, Wang W, Gu XS, Duan S (2007) Regulated ATP release from astrocytes through lysosome exocytosis. Nat Cell Biol 9:945-953. CrossRef Medline 